Article

\title{
Geointelligence against Illegal Deforestation and Timber Laundering in the Brazilian Amazon
}

\author{
Franco Perazzoni ${ }^{1,2, *(\mathbb{D})}$, Paula Bacelar-Nicolau ${ }^{3,4}{ }^{(\mathbb{D})}$ and Marco Painho ${ }^{5}(\mathbb{D})$ \\ Social Sustainability and Development (SSD), Universidade Aberta, 1269-001 Lisboa, Portugal \\ Commissioner of Federal Police, Brasília 70610-902, Brazil \\ Department of Sciences and Technology, Universidade Aberta, 1269-001 Lisboa, Portugal; pnicolau@uab.pt \\ Centre for Functional Ecology CEF, Universidade de Coimbra, 3000-453 Coimbra, Portugal \\ 5 NOVA Information Management School, Universidade Nova de Lisboa, 1070-312 Lisboa, Portugal; \\ painho@novaims.unl.pt \\ * Correspondence: perazzoni.fp@dpf.gov.br
}

Received: 15 April 2020; Accepted: 14 June 2020; Published: 17 June 2020

check for updates

\begin{abstract}
Due to the characteristics of the Southern Amazonas Mesoregion (Mesorregião Sul do Amazonas, MSA), conducting on-site surveys in all licensed forestry areas (Plano de Manejo Florestal, PMFS) is an impossible task. Therefore, the present investigation aimed to: (i) analyze the use of geointelligence (GEOINT) techniques to support the evaluation of PMFS; and (ii) verify if the PMFS located in the MSA are being executed in accordance with Brazilian legislation. A set of twenty-two evaluation criteria were established. These were initially applied to a "standard" PMFS and subsequently replicated to a larger area of 83 PMFS, located in the MSA. GEOINT allowed for a better understanding of each PMFS, identifying illegal forestry activities and evidence of timber laundering. Among these results, we highlight the following evidences: (i) inconsistencies related to total transport time and prices declared to the authorities (70\% of PMFS); (ii) volumetric information incompatible with official forest inventories and/or not conforming with Benford's law (54\% of PMFS); (iii) signs of exploitation outside the authorized polygon limits (51\% of PMFS) and signs of clear-cutting (43\% of PMFS); (iv) no signs of infrastructure compatible with licensed forestry ( $24 \%$ of PMFS); and (v) signs of exploitation prior to the licensing (19\% of PMFS) and after the expiration of licensing $(5 \%)$.
\end{abstract}

Keywords: amazon; Benford's law; deforestation; forestry management; geointelligence; organized crime; PMFS; RADAM; SisDOF; timber laundering

\section{Introduction}

According to official data, about $97 \%$ of the forests in the State of Amazonas were still preserved until 2012. However, in that same year, its annual deforestation rate reached $523 \mathrm{~km}^{2}$ (an increase of $4 \%$ when compared to 2011), and more recently reached a total of $1421 \mathrm{~km}^{2}$ during 2019, which represents about $14 \%$ of all that was deforested in the entire Amazon region in that period [1]. Such an increase in deforestation is due to multiple factors, among them the recent infrastructure works in the region, mainly roads. In addition to this, with the strengthening of preventive and repressive measures against illegal deforestation in the states of Mato Grosso, Rondônia, and Pará, historically the largest deforesters, the Amazonas state is today the last timber frontier in the Brazilian Amazon: illegal wood extracted from public areas there is of excellent quality and can be obtained at even lower cost than in other regions [2,3].

Forestry activities in the Brazilian Amazon presuppose the existence of authorization from a competent environmental administrative authority, which can be carried out in the form of a Sustainable 
Forest Management Plan (Plano de Manejo Florestal Sustentável, MFS), according to the provisions of the Brazilian Forest Code [4].

In brief, for the approval of a PMFS, the landowner must initially carry out a forestry inventory of the respective area, which contains the exact location of each tree, its species, and volume, and also identify protected specimens and seedlings such as those located in non-exploitable zones (e.g., hillsides and riversides).

Based on these data, the PMFS is prepared, following a series of legal requirements such as the dimensions of roads, storage yards, and with the limitation on the maximum volume to be explored as $25 \mathrm{~m}^{3} /$ ha [4].

These requirements aim to ensure that forestry activities will take place in a sustainable and planned way, respecting the mechanisms of sustaining the ecosystem. Indeed, one of the main elements to be considered by the environmental authorities in the licensing of a PMFS is the capacity of the natural regeneration of the managed species, and the landowners must commit themselves and carry out the forest exploitation in such a way as to promote the regeneration cycle of the area until new specimens replace those that have been cut [5].

Once the forest inventory and the PMFS is approved, designated trees may then be felled and sold. A PMFS account is created in the Forest Origin Document Management System (Sistema de Controle do Documento de Origem Florestal, SisDOF) of the Brazilian Institute of Environment and Renewable Natural Resources (Instituto Brasileiro de Meio Ambiente e dos Recursos Naturais Renováveis, IBAMA).

The SisDOF account works similarly to a bank account: forestry credits equivalent to the volume and species registered of the forest inventory are "deposited". These credits will be deducted with each sale and transferred from the PMFS to the account of the respective buyer at SisDOF by registering the respective transaction in the system and issuing a transport permit, called the Forest Origin Document (Documento de Origem Florestal, DOF), which follows the product to the destination and must be presented to the authorities in the case of inspections during the transportation [6]. Figure 1 represents the legal process of forest products from the PMFS to the timber industry.

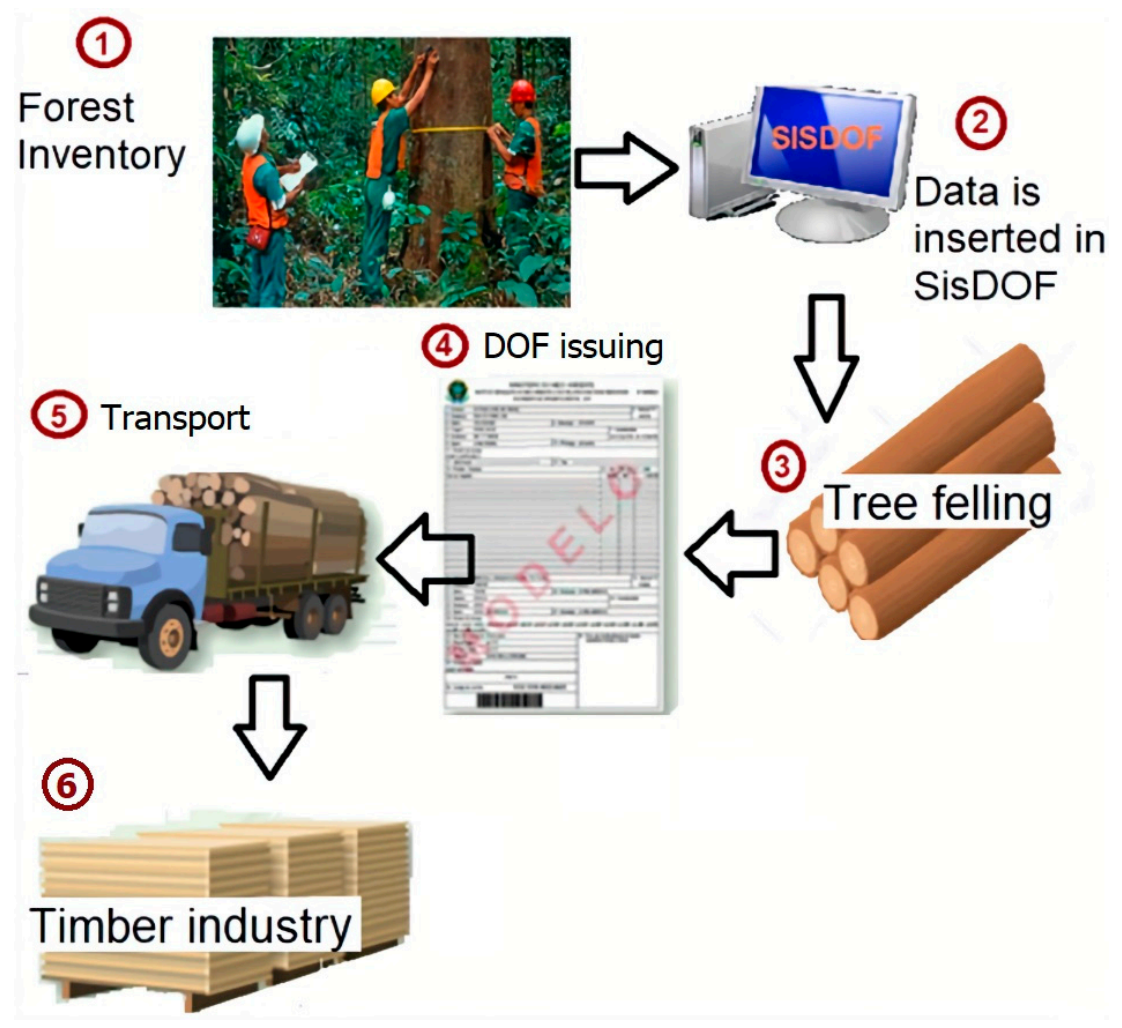

Figure 1. Visual outline of the legal timber trade process in Brazil. 
Unfortunately, the experience in combating illegal deforestation in the Brazilian Amazon shows that, in addition to the irregularities practiced inside the private rural properties authorized to carry out sustainable forest management (such as cutting intensity beyond the allowed limit, cutting of protected species or any species in Areas of Permanent Preservation (Áreas de Preservação Permanente, APP) such as hillsides and river banks), PMFS are also used by criminals for the legalization and trade of illegally obtained forest products from other private and public non-authorized areas such as indigenous lands and national parks [7-14]. Figure 2 represents the visual outline of illegal forestry in Brazil.

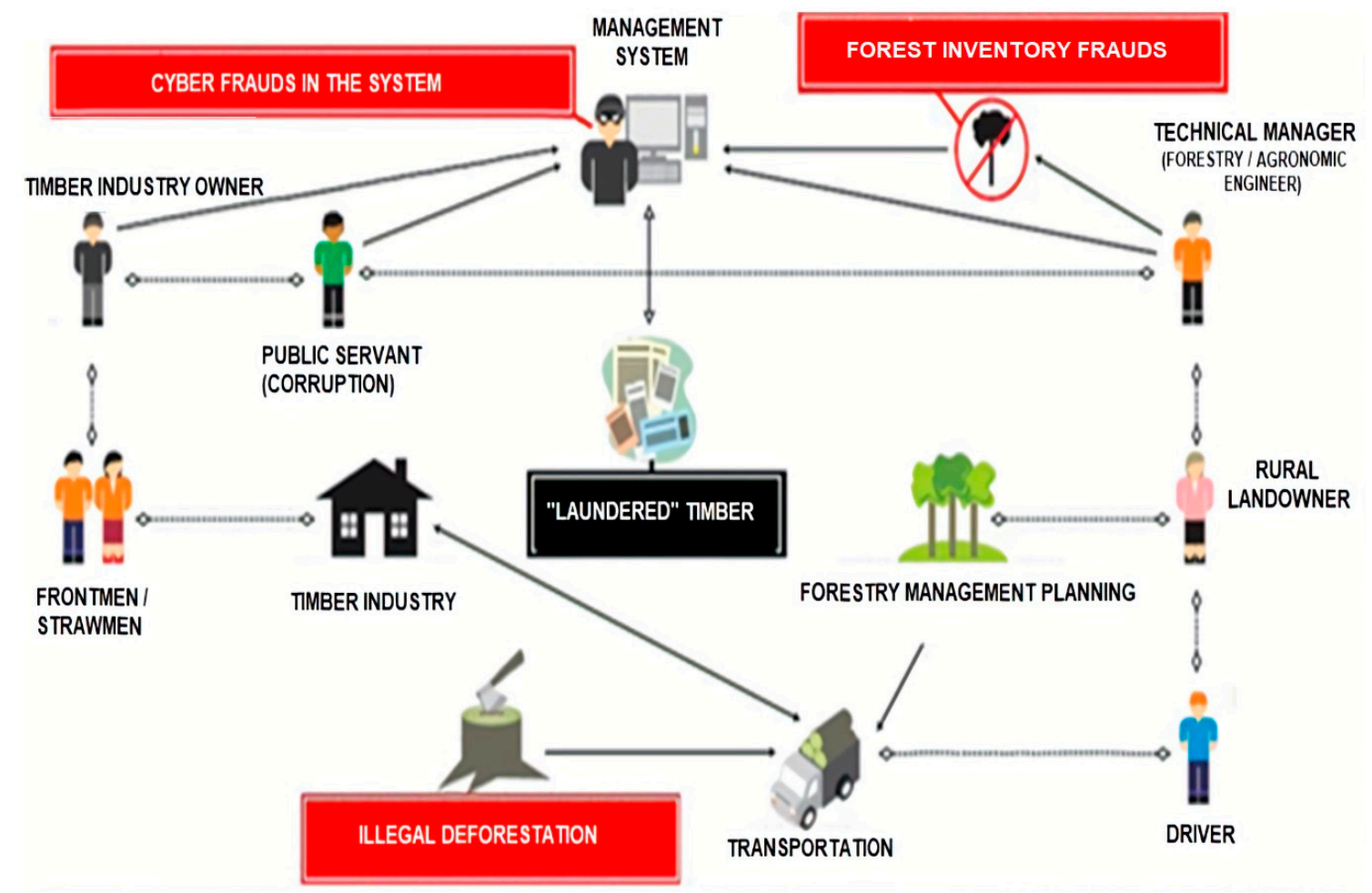

Figure 2. Visual outline of illegal forestry in Brazil (adapted from $[6,9])$.

Due to the characteristics of the Amazon region, conducting on-the-spot inspections with regularity and frequency in all areas of PMFS has proven to be unfeasible, notably due to the resources and time required, which greatly undermines state action in combating these crimes [14,15]. The present study seeks to demonstrate that such verification can be carried out successfully, based on geointelligence (GEOINT) techniques, especially from the multitemporal analysis of satellite sensor image analysis and its comparison with the official data contained in the SisDOF.

The rest of this article is organized as follows. In Section 2, a review of the literature is conducted regarding GEOINT and its application to the evaluation of PMFS in the Brazilian Amazon. Section 3 presents the objectives, materials, and methodology proposed. Section 4 presents the results, while the discussion and conclusions are presented in Sections 5 and 6, respectively.

\section{Literature Review}

Geointelligence (GEOINT) is defined by the National Geospatial-Intelligence Agency (NGA) as: "[...] exploitation and analysis of images and geospatial information to describe evaluate and visualize the physical features and georeferenced activities in the world. Geointelligence consists of: Images, Image Intelligence and Geospatial Information" [16]. The definition provided by the NGA proves to be quite satisfactory for the purposes of this work as it allows us to identify the three components of GEOINT, namely: (i) imagery; (ii) image intelligence (IMINT) and; (iii) geospatial information (Table 1). 
However, one has to keep in mind that this division is merely conceptual, and, in practice, the three components merge, as shown in Figure 3.

Table 1. Components of GEOINT (adapted from [16]).

\begin{tabular}{cl}
\hline Component & \multicolumn{1}{c}{ Characteristics } \\
\hline \multirow{2}{*}{ Imagery } & $\begin{array}{l}\text { Visual record of any resource or environment (natural or man-made), its objects, and related activities } \\
\text { that contain the respective geographic positioning data produced by satellites, aerial platforms, } \\
\text { unmanned aerial vehicles (UAVs), or other similar means. }\end{array}$ \\
\hline \multirow{3}{*}{ Image Intelligence } & $\begin{array}{l}\text { Technique of extracting useful information from the interpretation or analysis of images (for example: } \\
\text { the use of digital image processing techniques, vegetation indexes, classifications, etc.) and collateral } \\
\text { data (all that may contribute to the understanding and interpretation of images, including intelligence } \\
\text { data and information from other sources). }\end{array}$ \\
\hline \multirow{3}{*}{ Geospatial Information } & $\begin{array}{l}\text { Information related to the Earth's surface that identifies the location, geometry, and attributes of } \\
\text { environments, constructions, objects, resources or phenomena that occupy it (maps, statistical data, } \\
\text { tables, digital files, geoprocessing operations etc.). }\end{array}$ \\
\hline
\end{tabular}

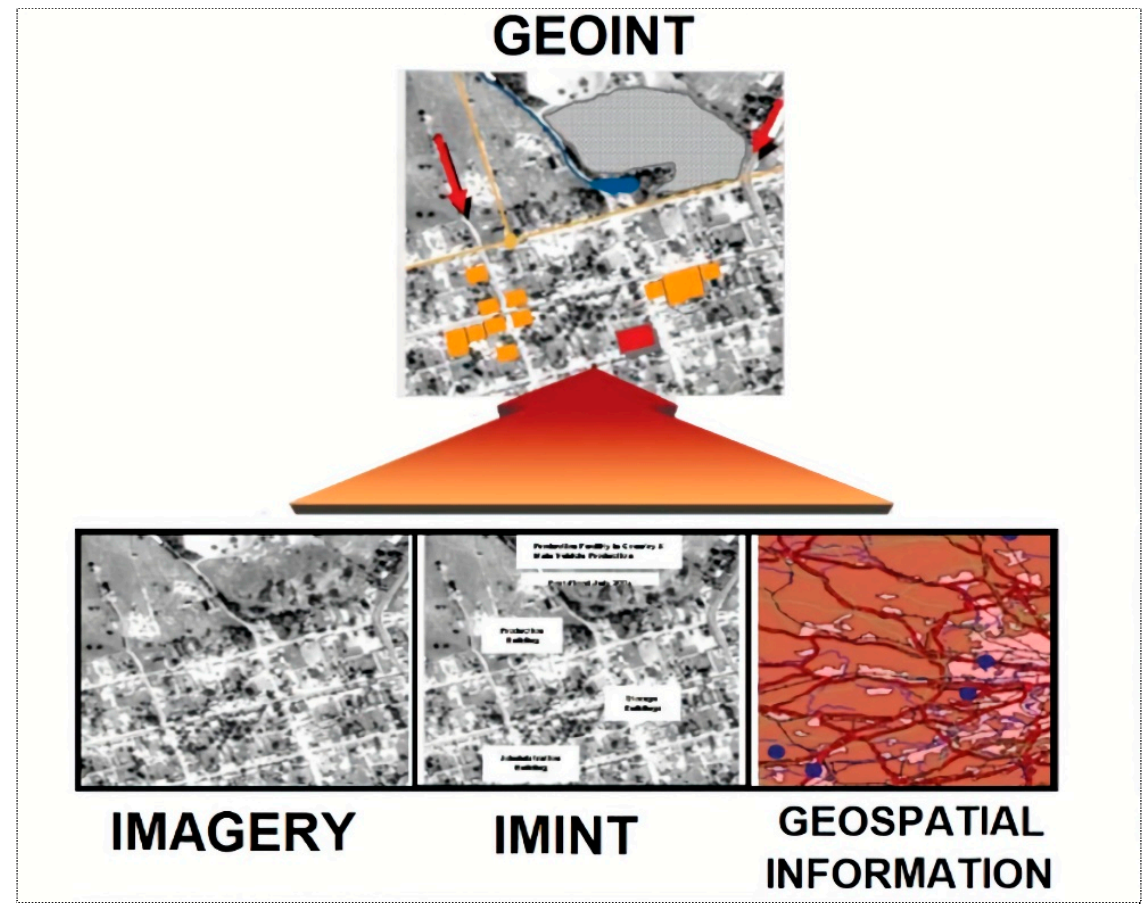

Figure 3. Components of GEOINT (adapted from [16]).

Despite its great increase in recent years, the scientific literature on GEOINT and its application in the evaluation of PMFS in the Brazilian Amazon is still relatively scarce. Part of this is due to the fact that the exploitation of wood through forest management is selective: only two to five trees per hectare $\left(<25 \mathrm{~m}^{3} / \mathrm{ha}\right)$, and satellite images available to the public are generally of medium or low resolution $[14,15,17]$. It was believed that it was not possible to evaluate PMFS on a large scale without resorting to high-resolution images, however, studies in the field of remote sensing have demonstrated for several years that it is possible to detect and evaluate the quality of logging with medium resolution satellite images and even estimate the impacts of exploitation on forest biomass [18-26]. In addition, a recent investigation demonstrated that Landsat images are useful for detecting logging activity in the same year of exploitation with the identification of storage yards larger than $290 \mathrm{~m}^{2}$ [27].

It should also be noted that several Brazilian government agencies such as the Brazilian Federal Environmental Agency (Instituto Brasileiro do Meio Ambiente e Recursos Naturais Renováveis, IBAMA) and the Brazilian Federal Police (Polícia Federal, PF) have used these technologies with relative success to detect irregularities in PMFS. This is possible because, even if there are serious limitations to the detection of the felling and dragging of trees in low and medium spatial resolution 
images, the infrastructure of the PMFS (consisting of storage yards and primary and secondary roads) can be detected and evaluated using this type of image. This allows for the mapping of selective wood exploitation, but also, in certain cases, estimation of their respective impacts $[25,28,29]$.

\section{Objectives, Materials and Methodology}

\subsection{Objectives}

The objectives of this research were:

- Evaluate how the use of GEOINT based on medium resolution imagery can be used on understanding the real situation of forest exploitation in areas authorized by the government in the Brazilian Amazon; and

- Verify if the PMFS of MSA are being carried out in compliance with the respective environmental standards, being truly sustainable, or whether laundering the timber illegally extracted from other areas.

\subsection{Materials}

The data for this research were obtained from public agencies, namely:

- Satellite imagery: multispectral Landsat 5 and 8 with a spatial resolution of $30 \mathrm{~m}$ made available to the public by the United States Geological Survey (USGS) [30];

- Geospatial information: polygons and other vector data of PMFS from the State of Amazonas Environmental Agency (Instituto de Proteção Ambiental do Amazonas, IPAAM) [31], protected areas (indigenous lands and national parks), roads, rivers, municipal boundaries, etc. from Chico Mendes Institute (Instituto Chico Mendes, ICMBio and National Indigenous People Foundation (Fundação Nacional do Índio, FUNAI) [32-35];

- Collateral materials:

i. Approximately 120 inspection and forensic reports by PF and IBAMA, related to frauds in PMFS [36,37];

ii. Data from the RADAM Project (Projeto Radar da Amazônia), a very comprehensive official collection of forest inventories, with species and respective volumes for approximately 2130 collection points, duly georeferenced, throughout the Brazilian Amazon made available to the public by the Brazilian Institute of Geography and Statistics (Instituto Brasileiro de Geografia e Estatística, IBGE) [38];

iii. Data related to administrative fines applied and areas embargoed by IBAMA and the National Secretary of Labor (Secretaria de Trabalho do Ministério da Economia, STME) [39,40];

iv. Identifying data for motor vehicles authorized to transport forest products in the Amazon as well as their carrying volume capacity from IBAMA [41]; and

v. SisDOF data referring to all commercial timber transactions carried out between 2013 and 2018 from IBAMA [42].

\subsection{Methodology}

\subsubsection{General Overview}

The research consisted of two stages: (i) the definition, based on an exploratory analysis of available materials (satellite imagery, geospatial information and collateral materials) and the study of the behavior of a "standard" PMFS, of a set of standard indicators (or analysis criteria) that could be applied to evaluate the regularity of PMFS; and (ii) the application of these criteria in relation to a number of PMFS in the defined study area.

The GEOINT methodology applied during this research was strongly influenced by the Kahaner Intelligence Cycle [43] and more specifically, its adaptation by Mellión [44]. 
Figure 4 illustrates how the Meillón model was applied for a better specification and methodological division of the two stages above described by dividing the research into the following steps:

- Planning phase (in red), composed in this case of the activities of definition of the standard PMFS and the study area as well as the data and resources necessary for the research;

- Collect phase (in green), consisting of the obtaining and initial validation of the data and resources necessary for the evaluation of the "standard" PMFS and the study area;

- Processing phase (in purple), consisting of the definition of tools and methods to be applied to each of the datasets (spatial and non-spatial) as well as the creation of the definitive dataset;

- Analysis phase (in blue), consisting of the integrated analysis of the data obtained and prepared in the previous phases and its documentation for later evaluation and comparison of the results;

- Diffusion phase (in orange), consisting of the presentation of the information obtained and the respective conclusions.

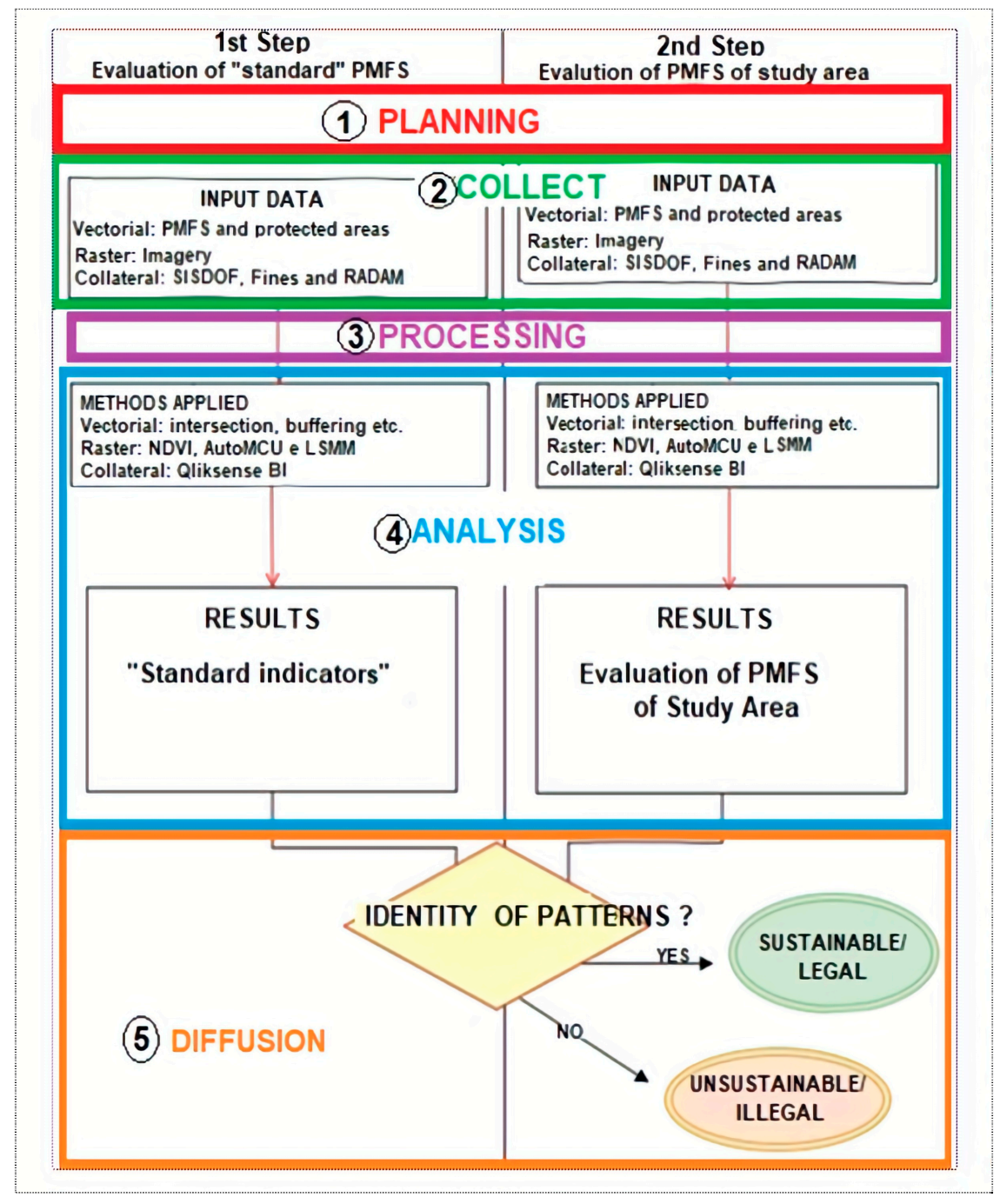

Figure 4. Flowchart of methodology.

In the following sections, each of the four methodological phases are synthetically described.

\subsubsection{Planning}

In this phase, the "standard" PMFS and the area of study area were defined as well as the data and resources necessary for the research. 
A "standard" PMFS was selected from an area that started its forestry activities in 1993 and has been certified by the Forest Stewardship Council (FSC) since 1997, the first to obtain this certification in Brazil [45]. The standard PMFS was distributed in nine different rural properties with a total area of approximately 270,000 ha, of which 139,000 ha were destinated for forestry management activities, subdivided into 47 production units, identified by the respective years of the cutting cycle (Figure 5) [46].

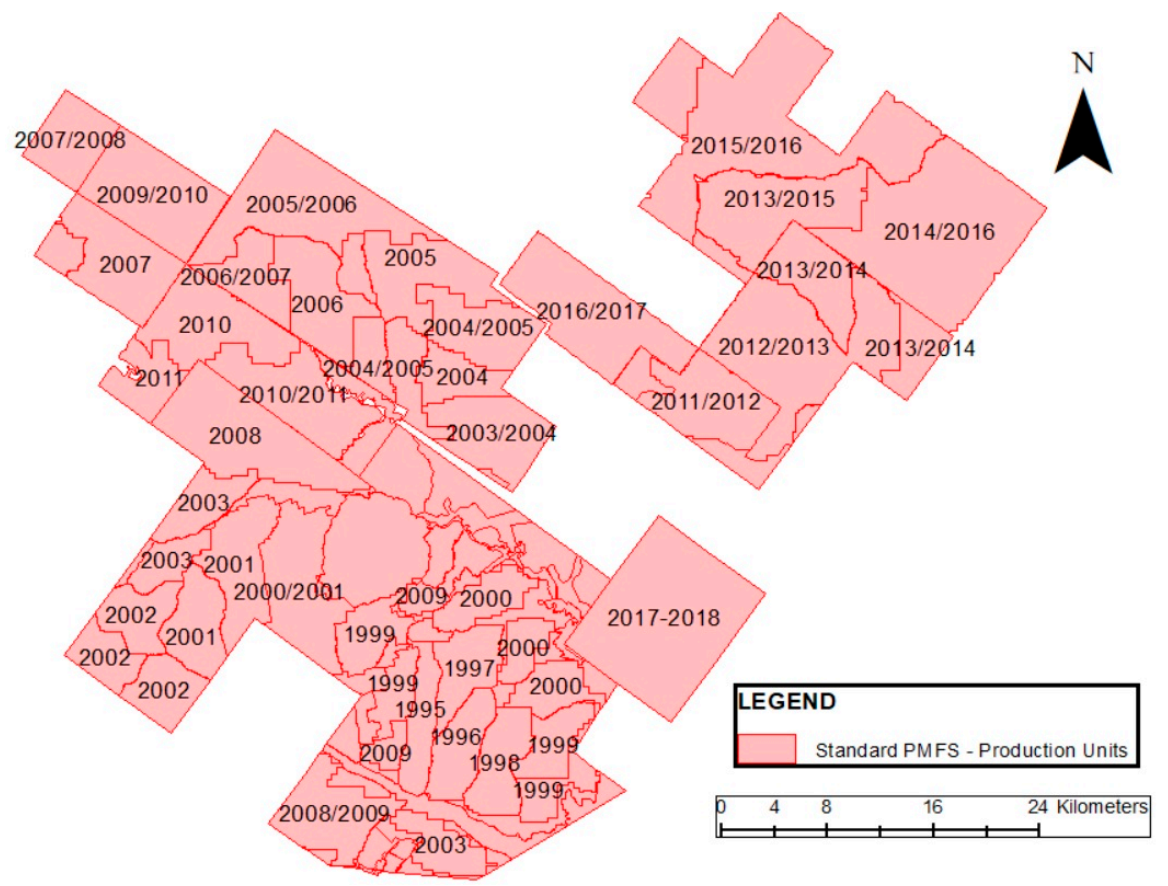

Figure 5. Standard Plano de Manejo Florestal (PMFS) production units (data from [46]).

The choice of the "standard" PMFS was based on research carried out in 2002 [47], which characterized them as follows:

- The PMFS area was planned to be exclusively exploited under the selective logging regime at a proportion of 2.5\% per year, between 2002 and 2022;

- $100 \%$ of commercial trees in the area were inventoried and the PMFS, approved by environmental agencies, was duly designed to prevent overexploitation;

- In addition to inventorying commercial species, the company carried out an inventory of $0.5 \%$ of the area $(1 / 200)$, one year before and one year after exploitation in order to understand the impact of logging on forest regeneration and species diversity.

- When settling in the region, the company came across about 50 families that already lived there, without, however, having the respective property titles. They were individuals who already lived there. The company chose to assign property rights to them instead of filing lawsuits to expel them. Most of these people were also employed at the company.

Additionally, the choice of the Southern Amazonas Mesoregion (Mesorregião Sul do Amazonas, MSA) as the study area (Figure 6) was justified by the fact that traded forestry products and illegal deforestation rates had been increasing yearly between 2014 and 2018 [1-3], and that according to SisDOF, $63 \%$ of all products traded in the Amazonas in the same period were from the MSA [42]. Likewise, most of the administrative fines for environmental offenses that occurred in Amazonas between 1996 and 2017 (88\%) also took place at the MSA [39], which makes this region the one with the highest incidence of irregularities and administrative fines in the State of Amazonas. 


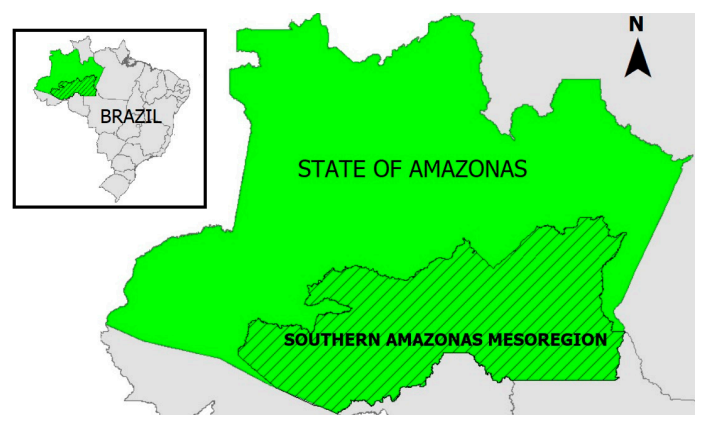

(a)

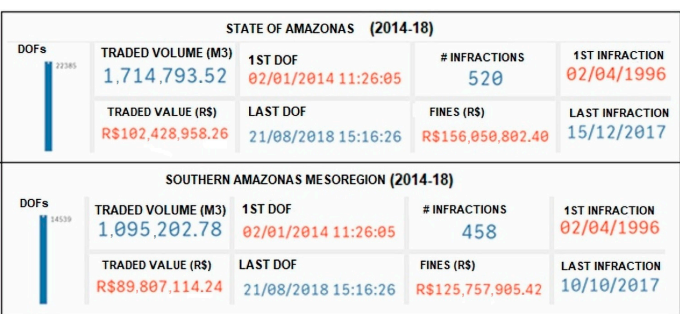

(c)

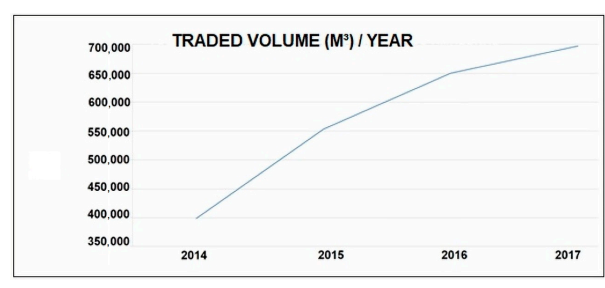

(b)

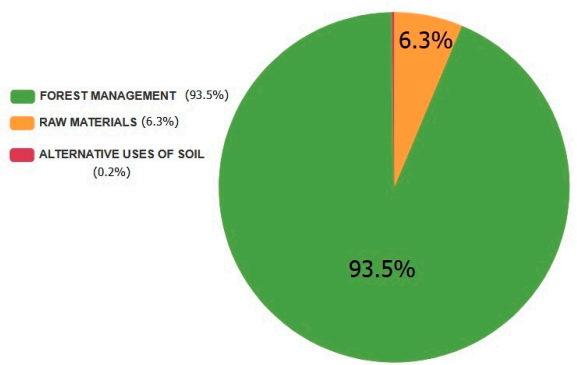

(d)

Figure 6. General information on Mesorregião Sul do Amazonas (MSA) [data from 42]. (a) Location, (b) traded volume per year, (c) comparison of State of Amazonas vs. MSA, (d) origin of timber production in MSA.

The study covered a period ranging from 2014 to 2018, corresponding to 83 licensed PMFS as shown in Figure 7.

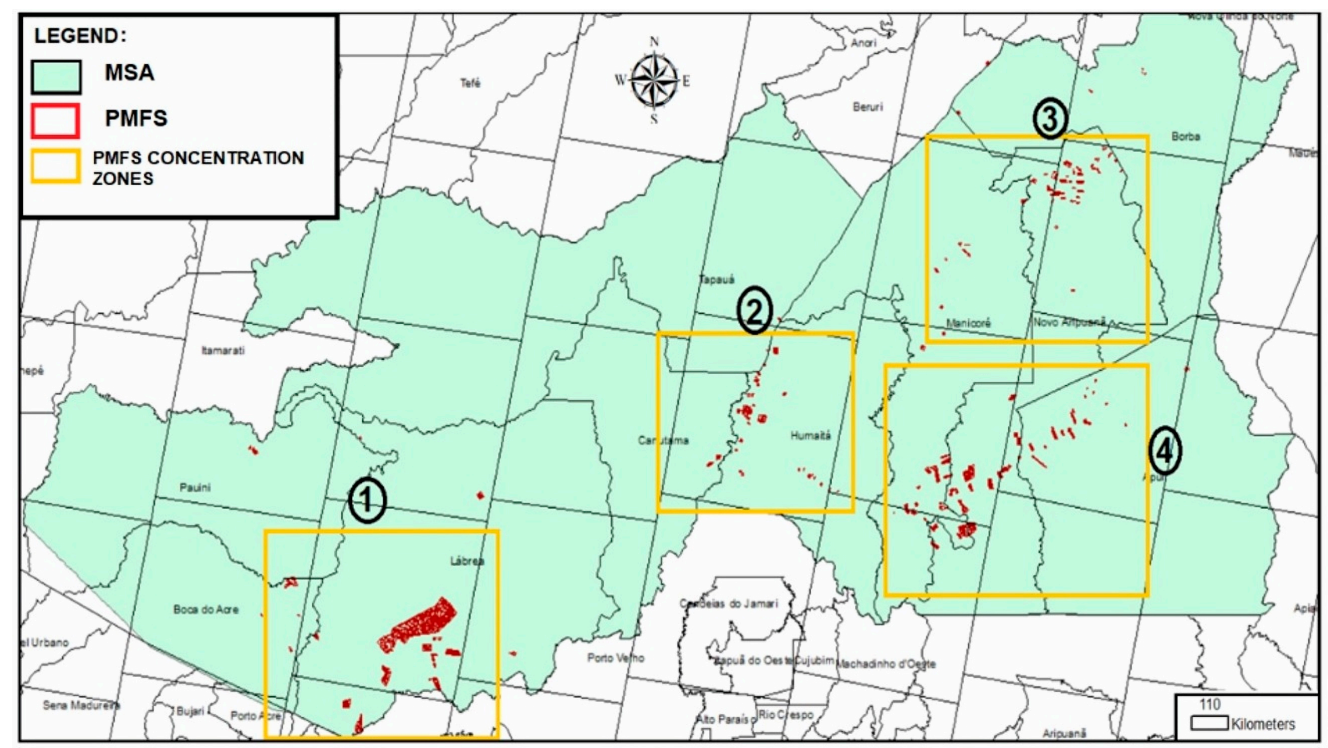

Figure 7. Overview of MSA and PMFS licensed in the years 2014-2018. Yellow rectangles show the main PMFS concentration areas.

\subsubsection{Data Collection}

The data collection phase consisted of obtaining and initially validating the data and resources mentioned in Section 3.2. Most data and resources are publicly accessible and were directly obtained through the websites of the above-mentioned bodies and entities. Additionally, the following were collected: (i) data of the polygons of the PMFS located in the MSA and all transactions carried out 
through SisDOF in the state of Amazonas, between 01/01/2014 and 08/21/2018, were obtained from the respective environmental agencies through the Federal Police's Environmental Crimes Enforcement Division [31,42]); (ii) data from the standard PMFS (polygons, inventories, etc.) were kindly provided by the technical responsible person [46]; and (iii) inspection and forensic reports from IBAMA and PF were obtained from the respective bodies, under commitment of their use for statistical purposes [36,37].

\subsubsection{Processing}

The processing phase consisted of the definition of the tools and methods to be applied to each of the datasets (spatial and non-spatial) as well as the creation of the definitive dataset. Initially, an exploratory evaluation of all reports produced by the PF and IBAMA as well as all other spatial and non-spatial data obtained, was carried out in order to identify the most common irregularities found on those PMFS. This resulted in the establishment of 22 evaluation criteria for PMFS (Table 2).

Table 2. Evaluation criteria for Plano de Manejo Florestal (PMFS).

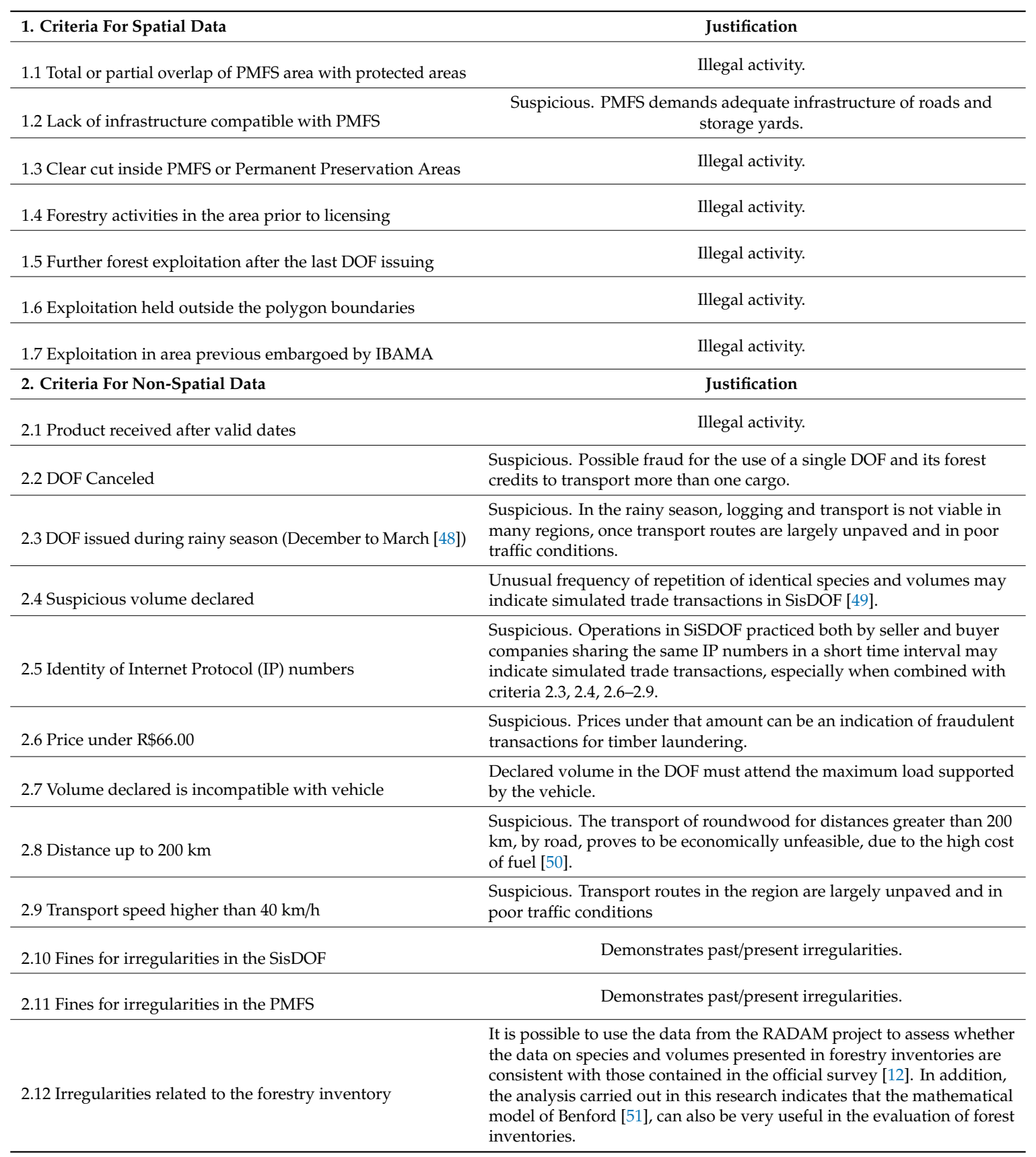


Table 2. Cont.

\begin{tabular}{ll}
\hline 2. Criteria For Non-Spatial Data & \multicolumn{1}{c}{ Justification } \\
\hline 2.13 Total volume traded identical to the authorized volume & $\begin{array}{l}\text { Suspicious. Losses occurs during the process of forest exploitation (logs } \\
\text { crack during the felling of trees), as also is common the presence of tree } \\
\text { hollows not measured in the original forestry inventory. }\end{array}$ \\
\hline 2.14 Fines for labor law violations & Demonstrates past/present irregularities. \\
\hline 2.15 Exploitation intensity over $25 \mathrm{~m}^{3} / \mathrm{ha}$ & $\begin{array}{l}\text { Illegal. The legislation of the state of Amazonas establishes that the } \\
\text { maximum exploitation intensity of PMFS is up to } 25 \mathrm{~m}^{3} / \mathrm{ha}^{177] .}\end{array}$ \\
\hline
\end{tabular}

Criteria 1.1 to 1.7 (spatial data) and 2.10, 2.11, and 2.14 (administrative fines applied for environmental or labor irregularities) focused on assessing the regularity of forest management, with a positive response to any of these items meaning irregularity.

Criteria 2.1 to $2.9,2.11$ to 2.13, and 2.15 (non-spatial data) were based on the information of the forestry inventory (2.12) and all data trade transactions in SisDOF (remaining items). These data, when analyzed together with the satellite imagery, indicate a greater or lesser degree of suspicion of the existence of frauds for the laundering and trade of forestry products illegally extracted from other areas.

Once the evaluation criteria were defined, the following methods and software were used to process and organize the image dataset:

- RGB composition using ArcMap 10.7.1 software: the resulting (true or false color) composition allowed for a better discrimination by visual observation of the targets and facilitated their interpretation);

- $\quad$ Automated Monte Carlo Spectral Unmixing (MTCU) using CLASlite 3.3 software [52]: uses a spectral mixture model associated with a robust spectral library to generate fractions that represent the main biophysical components of the landscape existing in a pixel [19,53]. The tool allows: (i) correction of atmospheric effects; (ii) derivation of fraction images corresponding to photosynthetically active vegetation (PV), non-photosynthetic vegetation (NPV) and bare soil (S); and (iii) multitemporal comparison of images, identifying situations of deforestation and forest degradation between two or more images.

- Normalized Difference Vegetation Index (NDVI) [54] through ArcMap 10.7.1 software: obtained by the ratio of the difference in reflectance of near infrared (NIR) and red (R) by the sum of them. It results in an index with values between -1 and 1 , where the presence of negative values or close to zero indicates the presence of areas of water or bare soil with little chlorophyll activity and thus low amount of vegetation; in turn, positive values indicate areas of vegetation.

- Linear Spectral Mixing Model (LSMM) using TerraAmazon 7.1.0 software. LSMM [55] allows for the estimation of the proportion of each component of the spectral mixture (soil, shadow, and vegetation), defining which one is the most representative within each pixel of the image. This is very useful in medium resolution images, especially because we there are three components radiating electromagnetic energy in the same pixel.

A dashboard was created for the non-spatial data (Figure 8) to allow for quick and easy consultation and analysis of criteria 2.1 to 2.15, as follows: (i) pie charts for viewing items 2.1 to 2.9; (ii) Key Performance Indicators (KPIs) referring to the start and end date of commercial transactions, volumes, and values of timber traded, administrative inspections, and total amount of fines; (iii) histogram containing the volumes traded over time; (iv) PMF general data (authorization \# and type, owner name, total area, authorized area, authorized volume $\left(\mathrm{m}^{3}\right)$ etc.; (v) data of traded timber species (volume, value, date of last transaction, $\mathrm{R} \$ / \mathrm{m}^{3}$ etc.); and (vi) official forest inventory data from the Brazilian government (Project RADAM) vs. forestry inventory of the PMFS. 


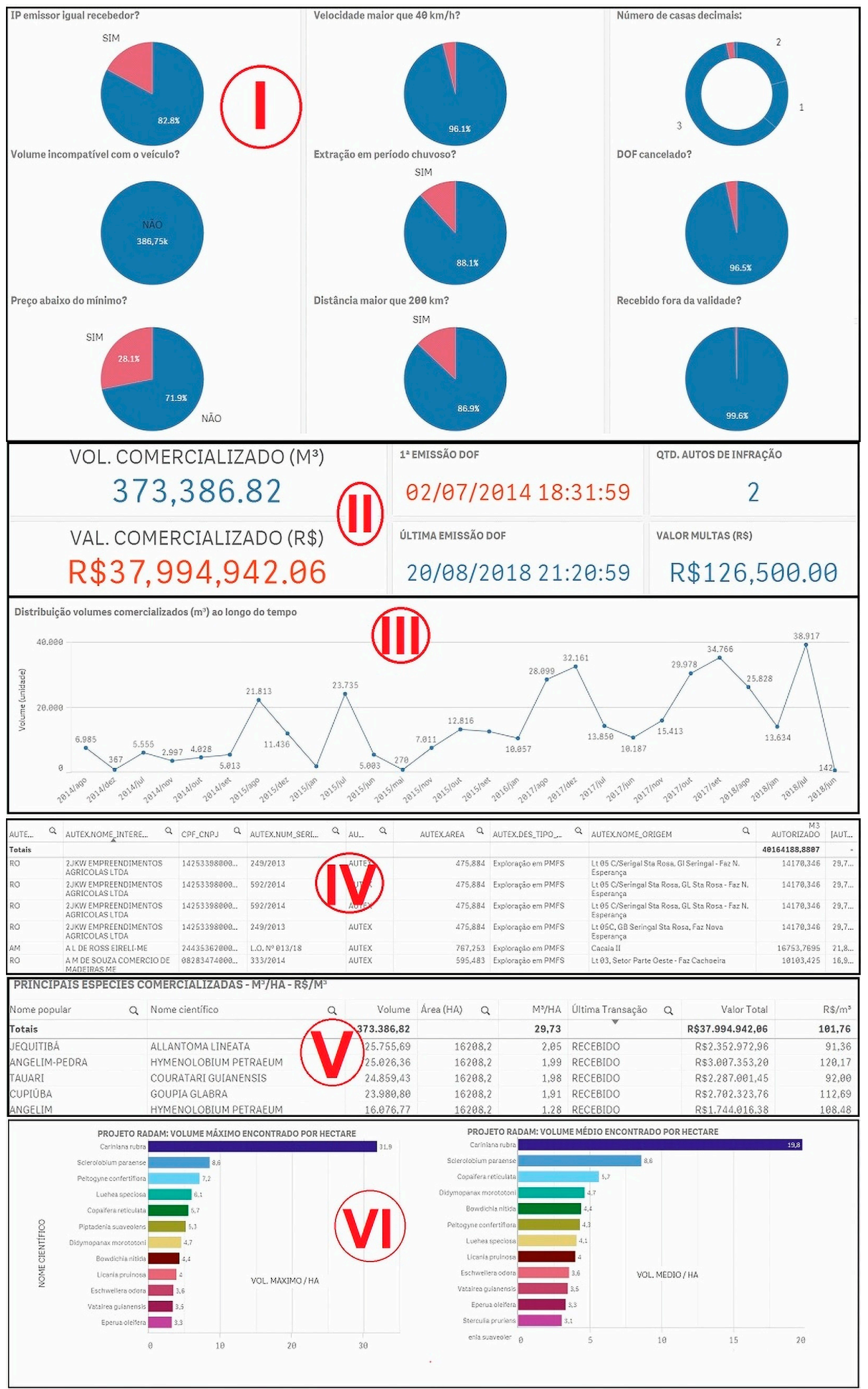

Figure 8. Dashboard for non-spatial data (original in Portuguese).

This dashboard was also combined with the electronic spreadsheet developed by Steven Miller [56] to test the applicability of the statistical model known as Benford's law for evaluating the data of forest inventories and roundwood volumes traded through SisDOF. This statistical model is applicable to specific datasets produced naturally (such as river areas, population, molar weights, atomic numbers, 
and mortality rates) and has been successfully used for decades to detect economic and financial fraud [57]. It considers the frequency probability of the first valid digit, that is, the leftmost digit, different from zero [56-58]. In contrast to a homogeneous distribution of the nine possible digits (1 to 9), which would correspond to the expected frequency of any digit being $11.11 \%$, Benford's law notes that the frequency follows a logarithmic behavior, represented by the formula:

$$
\mathrm{P}(\text { digit }=)=\log _{10}\left(1+\frac{1}{\text { digit }}\right)
$$

which means that the probability of the first digit being 1 is something close to $30.1 \%$, whereas digit 9 will appear in only about $4.6 \%$ of the observations [51,56-60].

Figure 9 allows us to understand, graphically, what would be the valid first digit and how the distribution of that digit occurs according to Benford's law.

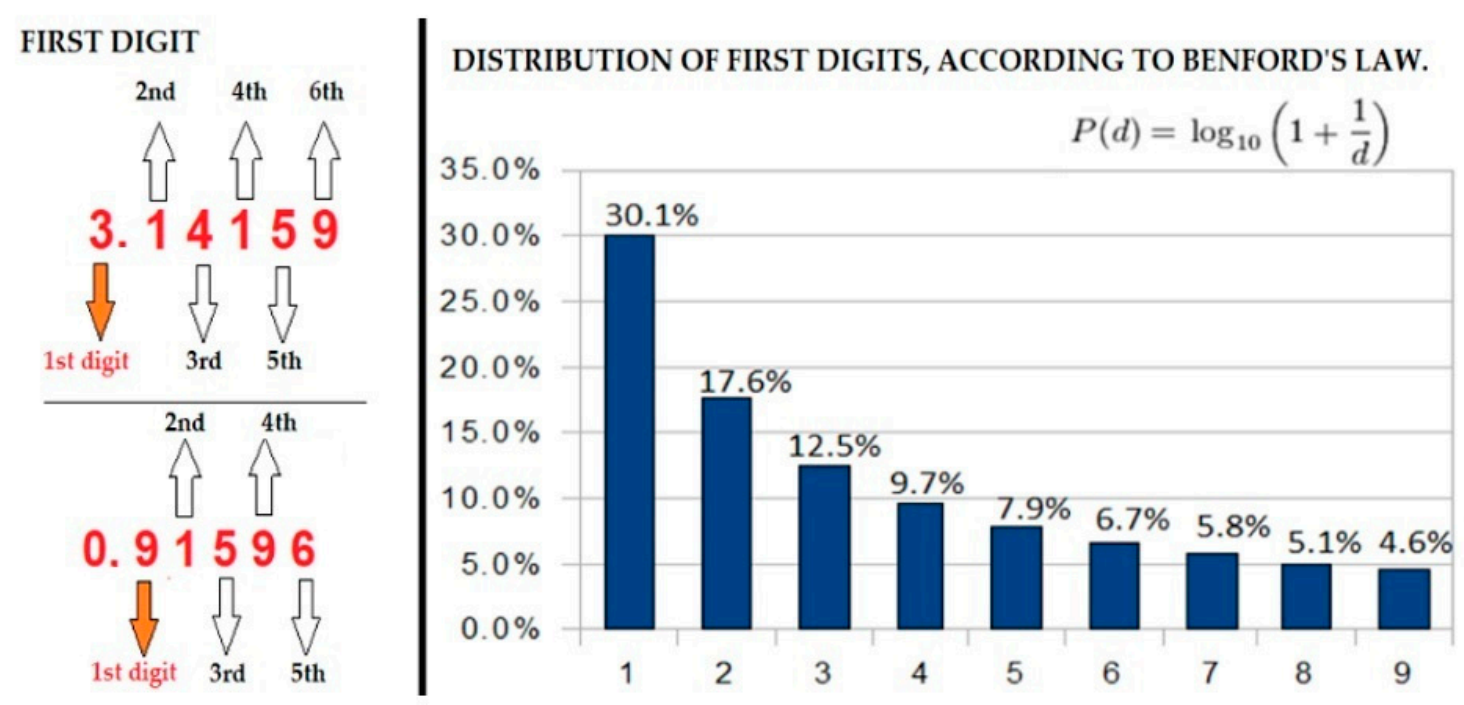

Figure 9. Distribution of first digits according to Benford's law.

\subsubsection{Analysis}

The above methodology was initially applied to the "standard" PMFS, which presented adequacy to most of the 22 evaluated criteria, except for the following findings: (i) criterion 1.6: exploitation outside the authorized polygon in 2009 ( 1 ha) and 2016 ( $\sim 3 \mathrm{ha})$; (ii) criterion 2.5: existence of a large number of transactions with the identity of Internet Protocol numbers (IPs) and; (iii) criterion 2.6: $31.1 \%$ of the total volume of roundwood traded during the rainy season. Furthermore, criteria 2.5 and 2.6 were not considered suspicious since the identity of IP numbers was not corroborated by other indications of fraud (criteria 2.3, 2.4, 2.6-2.9), and the standard PMFS had good transport infrastructure, being located near a paved highway.

This methodology was subsequently replicated to the 83 PMFS located in the MSA.

\section{Results}

\subsection{Preliminary Results Obtained during the Processing Phase}

During the processing phase, the analysis and comparison of data on roundwood volumes traded through SisDOF in the State of Amazonas from the years 2014 to 2018 as well as the official forest inventories contained in RADAM where it was found that the respective volumetric data presented a logarithmic distribution conforming to the theoretical model known as Benford's law $[51,60]$. The evaluation of conformance with Benford's law was based on the Chi-square adherence test. Although the level of significance most widely used in the verification of Benford's law is $5 \%$, it also 
uses a level of significance of $1 \%$ to minimize the probability of detecting the false evidence of fraud [58]. In both cases, eight degrees of freedom were used.

The following results were obtained:

- The volumetric data of all transactions contained in SisDOF for the State of Amazonas for both the total volume by species as well as the total volume of species traded per hectare presented conformity with Benford's law;

- The official volumetric data of the RADAM Project for both for total volume per species and total volume of species per hectare also showed conformity with the model;

- The sum of the "Diameter at Breast Height" (DBH) values of all individuals of the same species, per hectare, or totals for the entire study area also proved to be in conformity (RADAM volumetric data); and

- Changes in the data scale (daily, weekly, monthly, quarterly, half-yearly, or annual), did not significantly change the results obtained.

Figure 10 shows that the values obtained through the SisDOF [42] and RADAM [38] found strong conformity with this mathematical model.

\section{(a)}

$\begin{array}{rrr}\text { Digit } & \text { Benford Probability } & \text { Observed Probability } \\ 1 & 30.10 & 26.37 \\ 2 & 17.61 & 16.72 \\ 3 & 12.49 & 14.47 \\ 4 & 9.69 & 11.90 \\ 5 & 7.92 & 9.32 \\ 6 & 6.69 & 6.43 \\ 7 & 5.80 & 4.18 \\ 8 & 5.12 & 4.50 \\ 9 & 4.58 & 6.11\end{array}$

\section{Results:}

Cannot reject Null Hypothesis at $95 \%$ level Cannot reject Null Hypothesis at $99 \%$ level

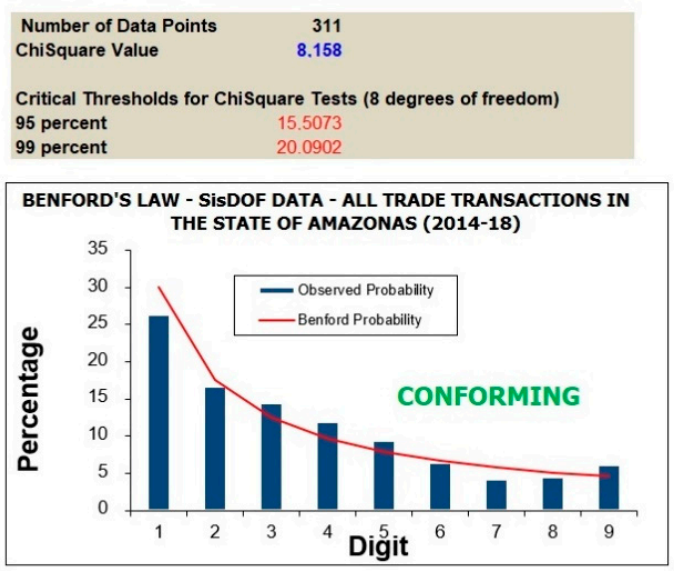

(a)

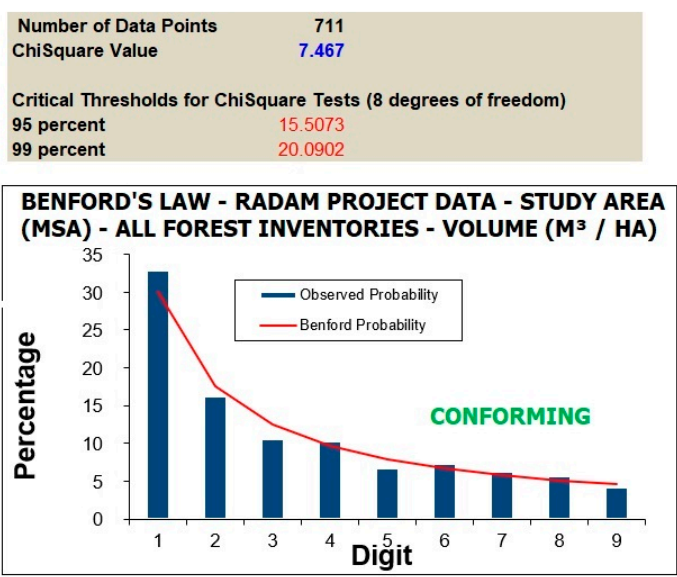

(b)

Figure 10. Cont. 
(c)

$\begin{array}{rrr}\text { Digit } & \text { Benford Probability } & \text { Observed Probability } \\ 1 & 30.10 & 30.38 \\ 2 & 17.61 & 16.60 \\ 3 & 12.49 & 10.69 \\ 4 & 9.69 & 9.56 \\ 5 & 7.92 & 7.45 \\ 6 & 6.69 & 7.74 \\ 7 & 5.80 & 7.03 \\ 8 & 5.12 & 5.77 \\ 9 & 4.58 & 4.78\end{array}$

Results:

Cannot reject Null Hypothesis at $95 \%$ level

Cannot reject Null Hypothesis at $99 \%$ level

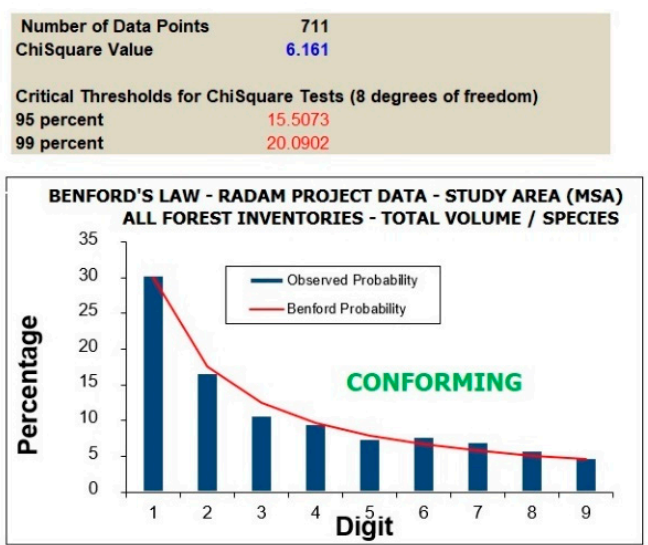

(c)

Figure 10. Volumes of timber obtained through SisDOF and RADAM vs. Benford's law. (a) All transactions in the State of Amazonas in SisDOF (2014-2018), (b) RADAM data for MSA ( ${ }^{3} / \mathrm{ha}$ ), (c) RADAM data for MSA (total volume/species).

Similarly, it was found that the total volume traded in the State of Amazonas from 2014 to 2018 of Allatoma lineata (jequitibá) conformed with Benford's law (Figure 11), but the same analysis for the traded volumes of Tabebuia serratifolia (ipê), a species that is known to be fraudulently overestimated in forestry inventories due to its high commercial value [12], did not conform to Benford's law (Figure 12).

$\begin{array}{rrr}\text { Digit } & \text { Benford Probability } & \text { Observed rrobability } \\ 1 & 30.10 & 28.40 \\ 2 & 17.61 & 20.37 \\ 3 & 12.49 & 17.28 \\ 4 & 9.69 & 8.02 \\ 5 & 7.92 & 6.17 \\ 6 & 6.69 & 8.02 \\ 7 & 5.80 & 4.94 \\ 8 & 5.12 & 4.32 \\ 9 & 4.58 & 2.47\end{array}$

\section{Results:}

Cannot reject Null Hypothesis at $95 \%$ level Cannot reject Null Hypothesis at $99 \%$ level

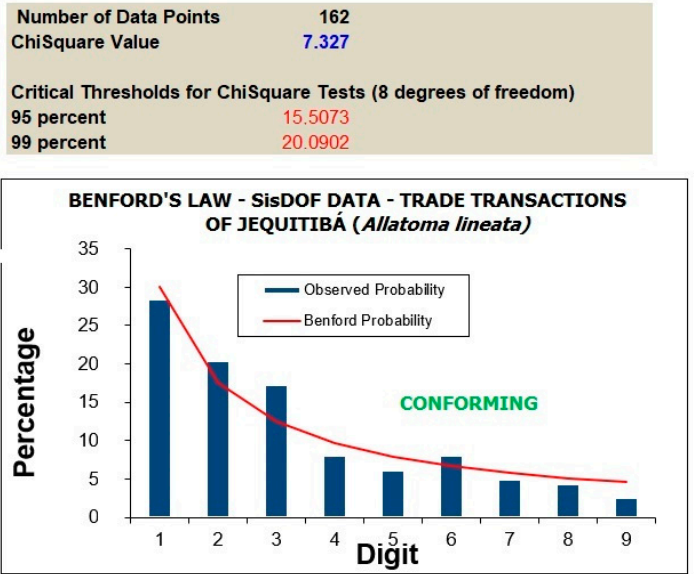

Figure 11. SisDOF trade data of Allantoma lineata (2014-2018) vs. Benford's law.

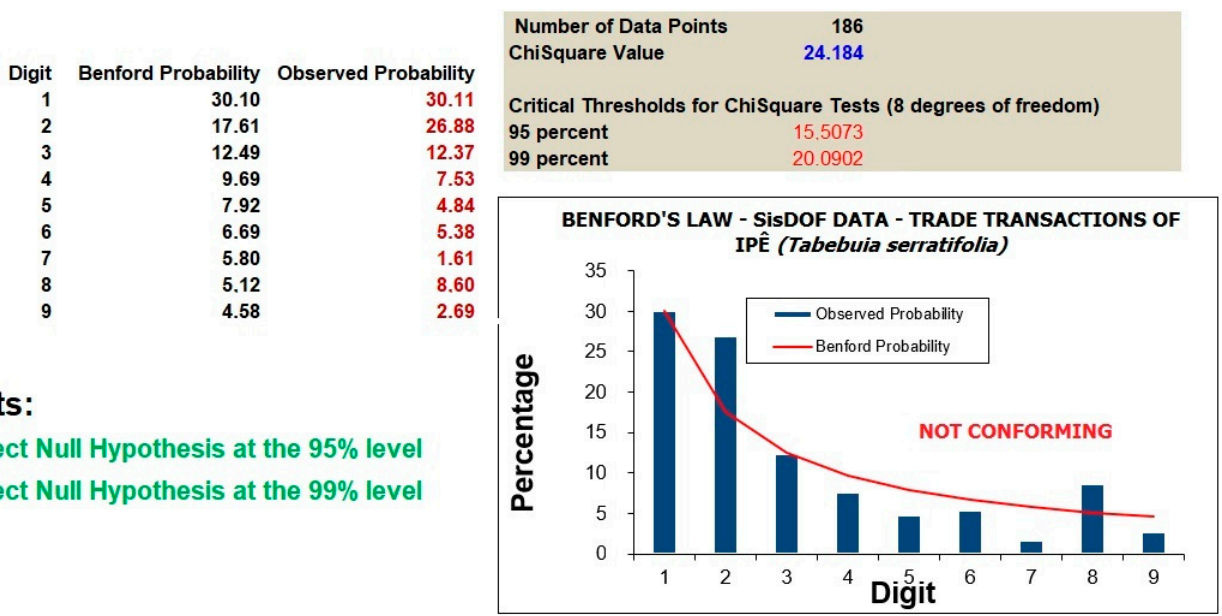

Figure 12. SisDOF trade data of Tabebuia serratifolia (2014-2018) vs. Benford's law. 


\subsection{Analysis Results}

The results of the spatial analysis are presented for comparison purposes for both the standard PMFS and the 83 PMFS evaluated. Similarly, the results of non-spatial analysis are also presented for both the standard PMFS and the 83 PMFS evaluated as well as for all the PMFS in the State of Amazonas and those located in the MSA, whenever the data were available.

Some figures are shown as examples of the irregularities found for a better understanding.

PMFS were identified by its feature identification number (FID), with no mention of individualizing data such as names, geographic coordinates, etc.

\subsubsection{Spatial Data}

(i) Criterion 1.1-Total or partial overlap of the PMFS area with protected areas

Standard PMFS: No overlapping of the standard PMFS with protected areas identified (Figure 13).

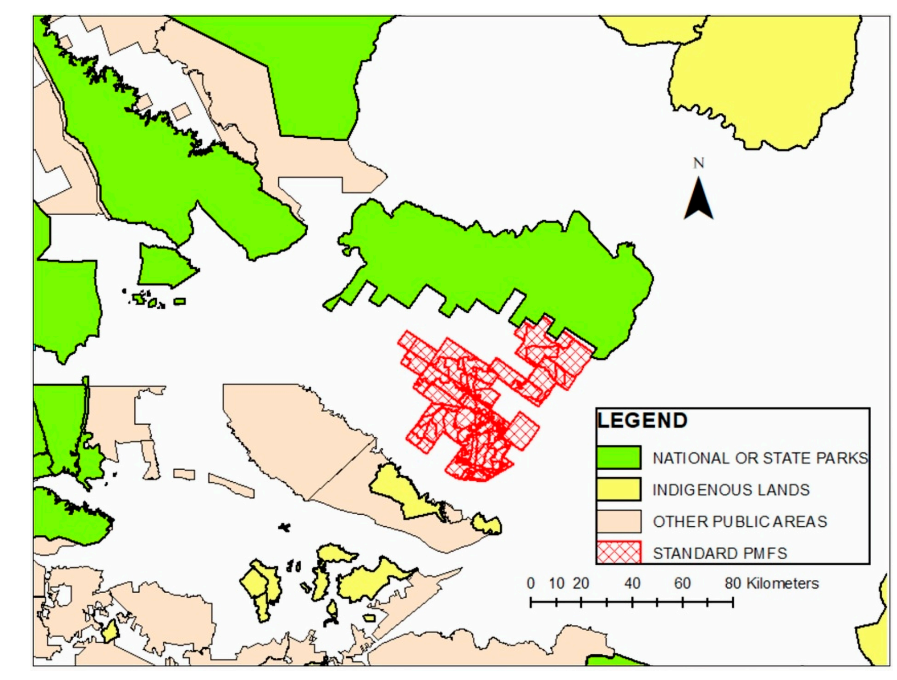

Figure 13. General overview of standard PMFS and near protected areas.

MSA PMFS: 10\% (8 PMFS) totally or partially inside National Forests (Figure 14). 06 PMFS (FIDs 107, 304, 124, 406, 159 and 1904) totally overlapped with National Forests. FIDs 1325 and 3826 had partial overlap. All these areas presented signs of exploitation what can indicate that overlapping was not just error in polygon creation, georeferencing, etc.

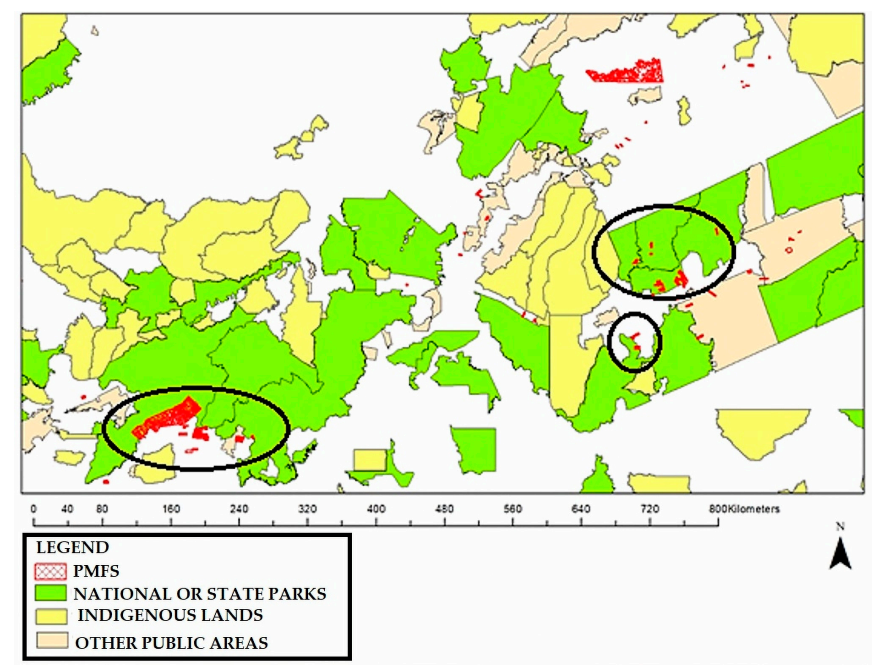

Figure 14. General overview of MSA. Black circles correspond to PMFS overlap with protected areas. 
(ii) Criterion 1.2-Lack of infrastructure compatible with PMFS (storage yards and roads)

Standard PMFS: There are infrastructures of roads and yards in the standard PMFS during the effective exploitation (Figure 15).

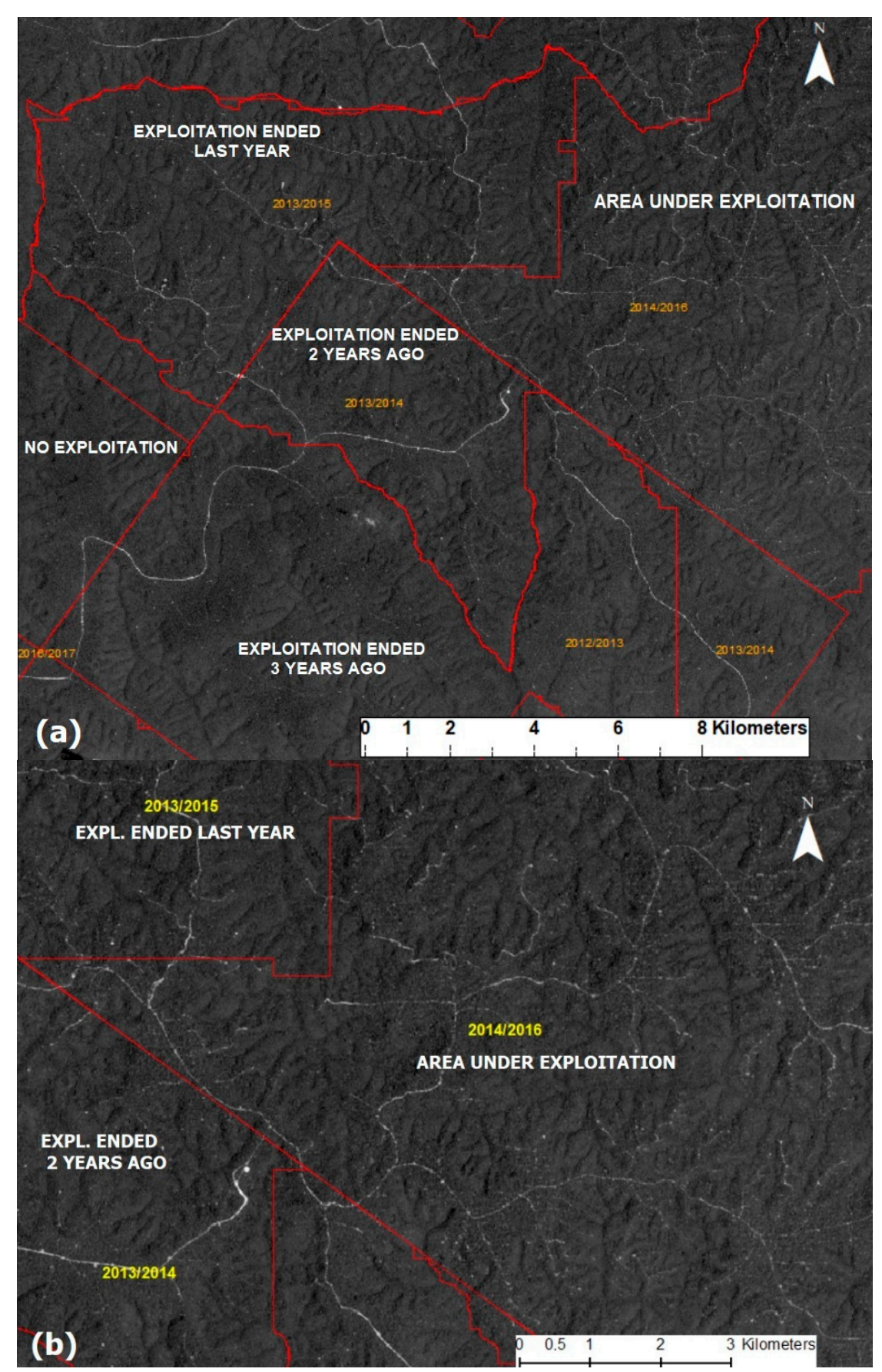

Figure 15. Presence of storage yards and roads during selective logging (NDVI) inside red polygons representing standard PMFS and its annual units of production. (a) scale bar: $8 \mathrm{~km}$, (b) scale bar: $3 \mathrm{~km}$.

MSA PMFS: 20 PMFS (24\% of the sample) had infrastructure incompatible with forest management practices, 10 referring to cases of no sign of yards and roads in the area and 10 referring to situations incompatible with PMFS and/or the volumes traded from these areas. Figure 16 shows complete absence of infrastructure and signs of selective logging inside PMFS. 


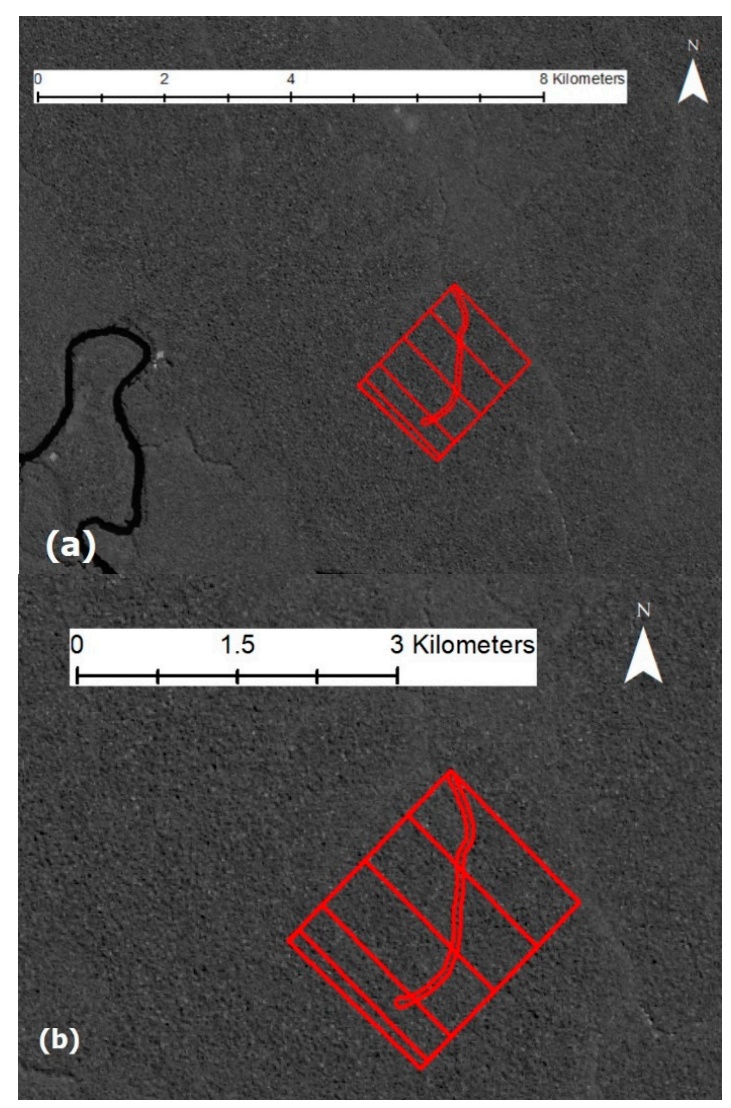

Figure 16. Complete absence of infrastructure and signs of selective logging (NDVI) inside red polygon representing PMFS (FID 1791). (a) scale bar: 8 km, (b) scale bar: $3 \mathrm{~km}$.

(iii) Criterion 1.3-Deforestation in the PMFS and/or Areas of Permanent Preservation (APP)

Standard PMFS: Between the years 1993 and 2004, there was an increasing deforestation of APP located in the southeastern portion of the PMFS, which was possible to detect thru MTCU (Figure 17).

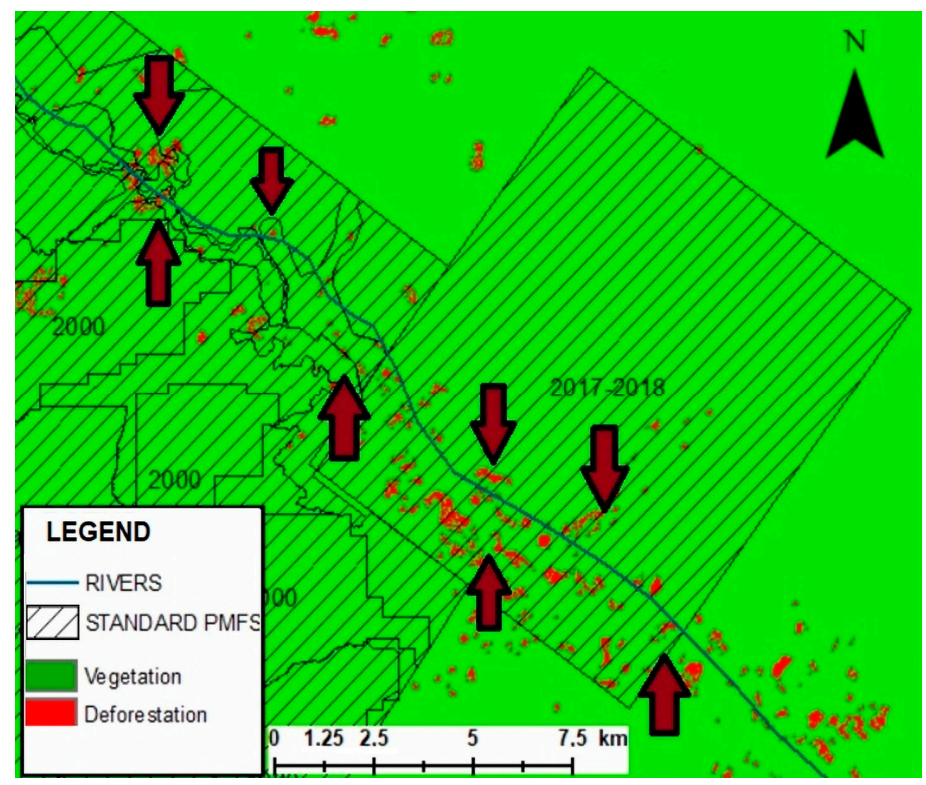

Figure 17. Red arrows point to deforestation (red areas) that occurred in APP of the standard PMFS (dashed polygons) between the years 1993 and 2004 (MCTU). 
MSA PMFS: 36 properties (43\%) showed signs of clear-cutting in their interior, among which 23 presented deforestation that reached APPs. Figure 18 shows deforestation in the PMFS (FID 3364).

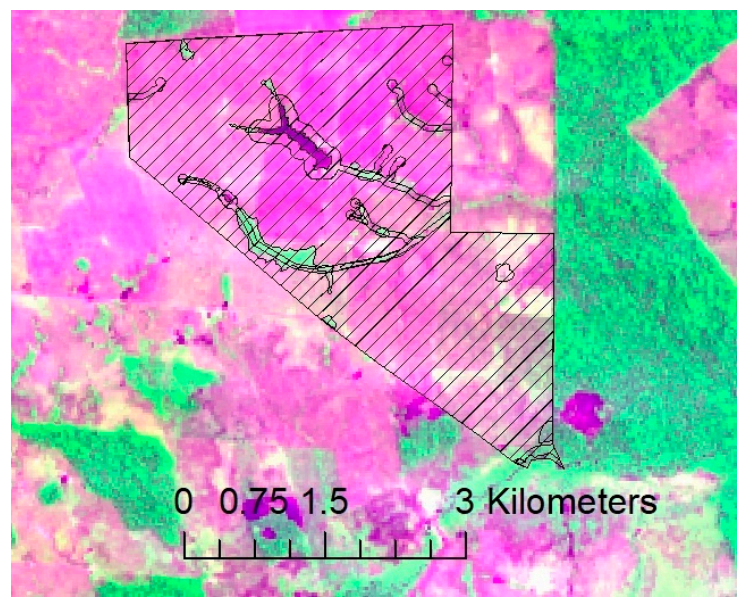

Figure 18. Deforestation in the PMFS (FID 3364). Inside and around the dashed polygon corresponding to the PMFS limits, there is a predominance of reddish hue, with a regular shape and smooth texture, compatible with bare soil.

(iv) Criterion 1.4-Forest exploitation in the area prior to licensing

Standard PMFS: No forest exploitation in the standard PMFS prior to licensing identified.

83 MSA PMFS: 19\% of the areas showed signs of exploitation prior to the licensing. Figure 19 shows presence of yards, roads and selective cutting signs inside three PMFS (4888, 2987 and 4191).

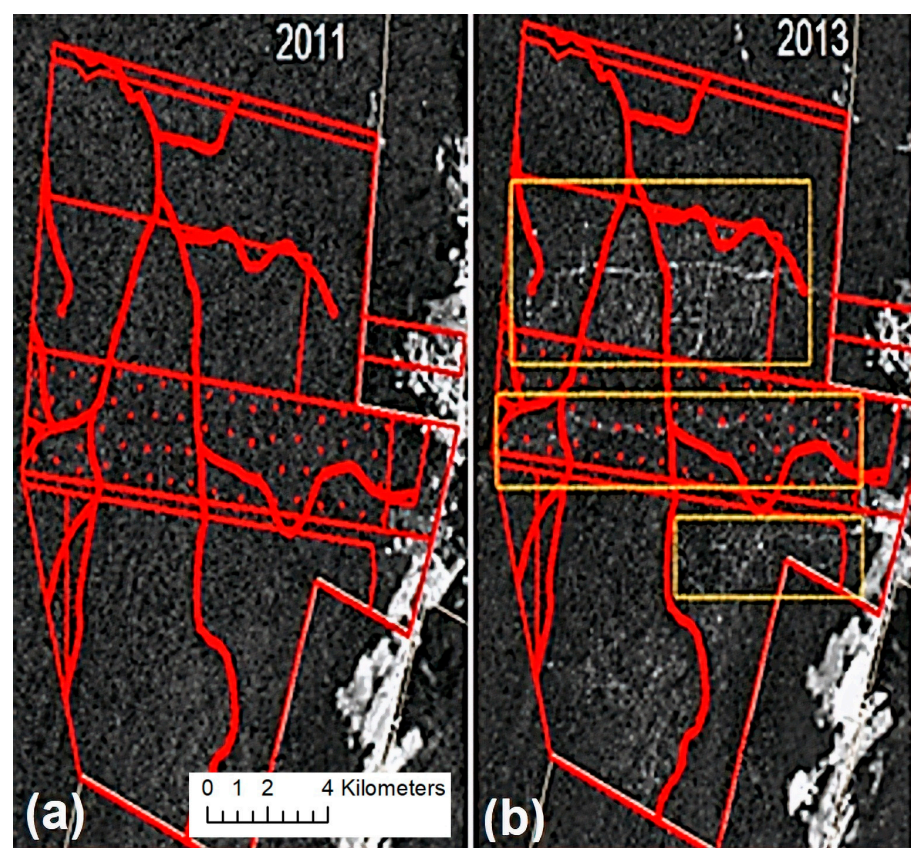

Figure 19. Yellow rectangles indicate presence of yards, roads and selective cutting signs (NDVI) inside three PMFS (red polygons-FIDs 4888, 2987 and 4191) between August/2011 (a) and August/2013 (b), despite the SisDOF transactions starting only in June/2014.

(v) Criterion 1.5-Further forest exploitation after the last DOF issuing

Standard PMFS: No forest exploitation in the standard PMFS after the last DOF issuing. 
83 MSA PMFS: $5 \%$ of the areas showed signs of exploitation after the last DOF issuing. Figure 20 shows areas of selective cut inside and around PMFS (FID 4572).

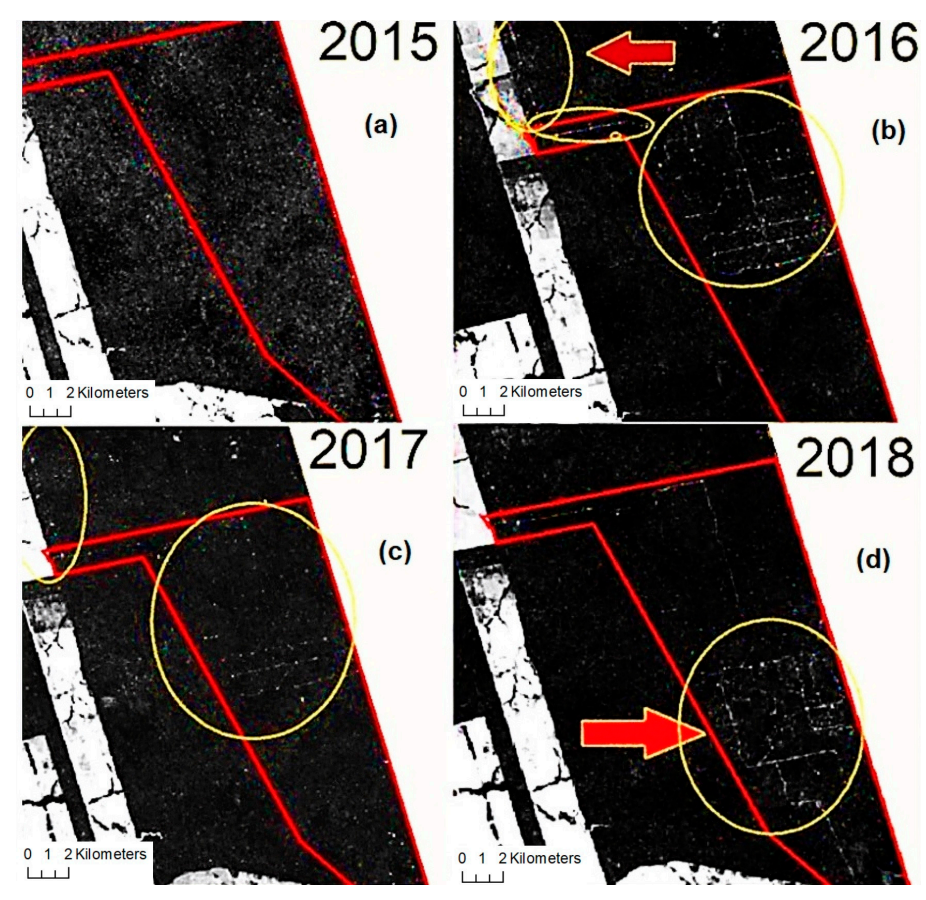

Figure 20. Exploitation in the area between 2016 (b), 2017 (c) and 2018 (d), after the last DOF issue in 2015 (a). Yellow circles indicate areas of selective cut inside and around the PMFS polygon in red (FID 4572).

(vi) Criterion 1.6-Exploitation held outside the polygon boundaries

Standard PMFS: It was detected selective exploitation outside the authorized polygon in years 2009 and 2016 (Figure 21).
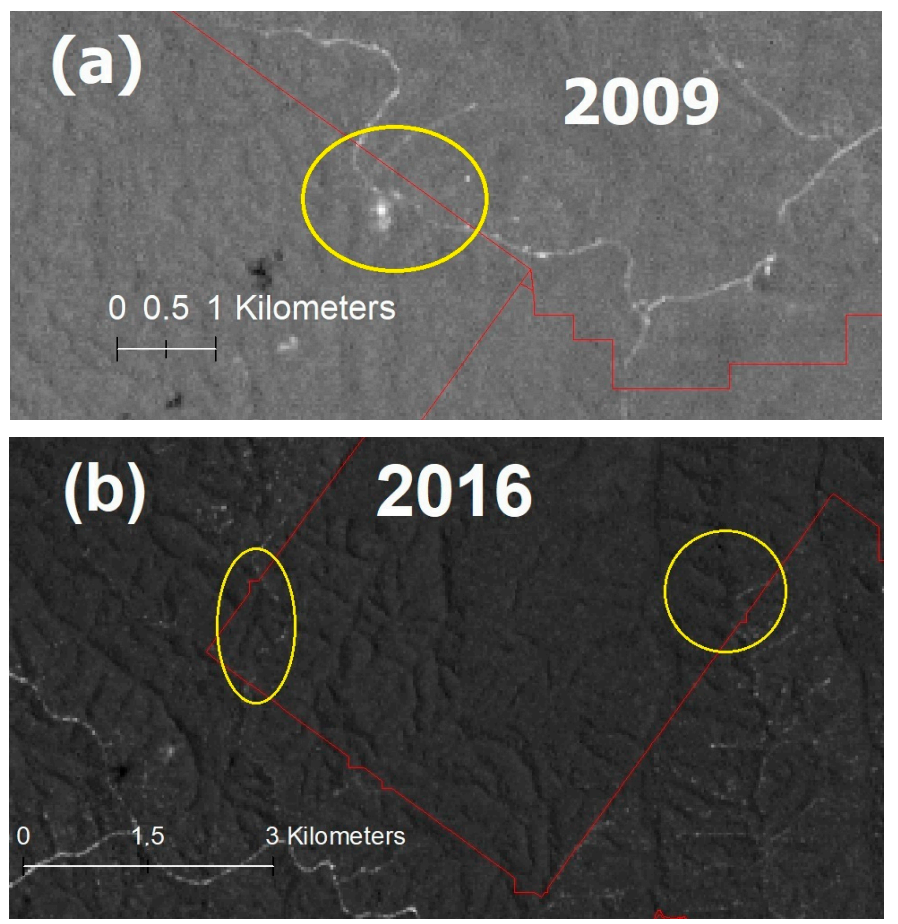

Figure 21. Yellow circles identify areas explored outside the authorized PMFS polygon (in red). (a) NDVI-2009 ( 1 ha), (b) NDVI-2016 ( 3 ha). 
MSA PMFS: 43 PMFS (52\%) showed signs of exploitation (selective and/or clear cut) outside the authorized polygon limit. Figure 22 shows exploitation carried out outside PMFS (FIDs 4888, 2987 and 4191).

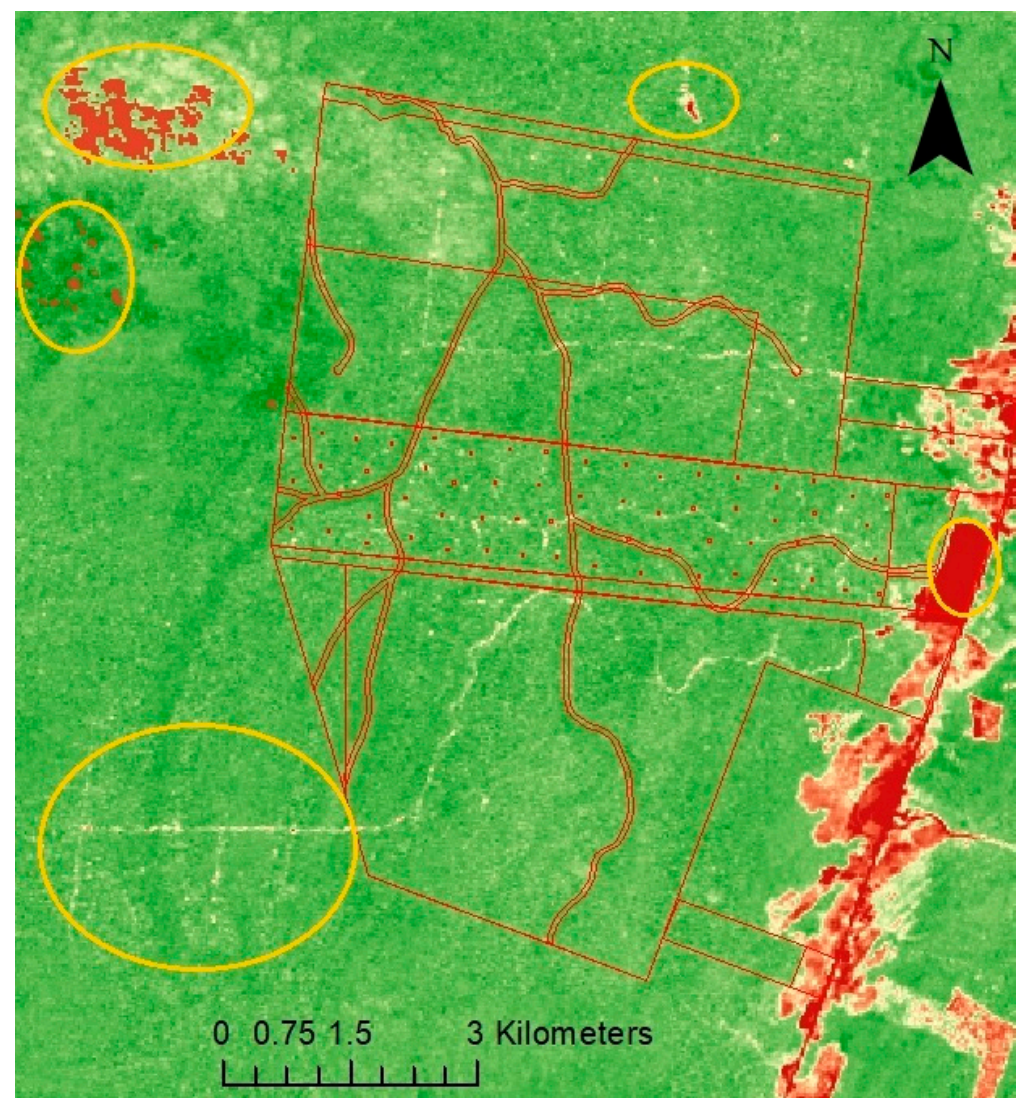

Figure 22. Exploitation carried out outside the limits of the polygonal. Yellow circles identify areas explored outside the authorized PMFS polygon in red (FIDs 4888, 2987, and 4191).

(vii) Criterion 1.7-Exploitation in area previous embargoed by IBAMA

Standard PMFS: No exploitation in area previous embargoed by IBAMA identified inside standard PMFS.

83 MSA PMFS: No exploitation in area previous embargoed by IBAMA identified inside MSA 83 PMFS.

\subsubsection{Non-Spatial Data}

(i) Criterion 2.1-Product received after valid dates

STATE OF AMAZONAS: $5.8 \%$.

MSA: $3.6 \%$.

STANDARD PMFS: $0.5 \%$.

MSA 83 PMFS: $17 \%$ of the areas issued DOFs received only later than the end of the document's validity in a percentage greater than $5 \%$ of the total number of documents issued. The highest percentile of products received out of date was 49.7\% (FID 4940), out of about $6800 \mathrm{~m}^{3}$.

(ii) Criterion 2.2-DOF Canceled 
MSA: $3.7 \%$.

STANDARD PMFS: $0.9 \%$.

MSA 83 PMFS: $20 \%$ of the areas had DOFs canceled at a level higher than $5 \%$ of the total volume sold. FID 3303 had a canceled volume of $28.2 \%$ (of an amount of $\sim 2700 \mathrm{~m}^{3}$ ), above all other PMFS that were between 5 and $8.1 \%$.

(iii) Criterion 2.3-DOF issued during rainy season (December to March)

STATE OF AMAZONAS: $16.5 \%$.

MSA: $13.7 \%$.

STANDARD PMFS: $31.3 \%$. It should be noted that the standard PMFS has a good access road structure and it is located close to a highway, which would, in theory, allow exploration throughout the year. Most PMFS located in Amazonas and specially in MSA, however, do not have such structure.

MSA 83 PMFS: 24\% of the areas had DOFs issued during the rainy season at a level higher than $15 \%$ of the total volume sold. Anyway, some of the properties had volumes extracted in the rainy season above the average such as FID 2262 (32.5\%) and FID 3468 (44.7\% and 37\%). FIDs 4936 and 4499 , despite being areas belonging to the same holder and being located very close, had their exploitation the in rainy season carried out quite differently, with $1 \%$ of exploitation during the rainy period in FID 4936, against 44.3\% of exploitation at the same time for FID 4499 (Figure 23). This finding, in addition to various other irregularities found for both FIDS, may show fraudulent transactions in SisDOF. However, this is an indicator that must be evaluated in each specific case, together with other factors such as the existence of roads and adequate infrastructure for the extraction and transportation of products, distance to the recipient, etc.

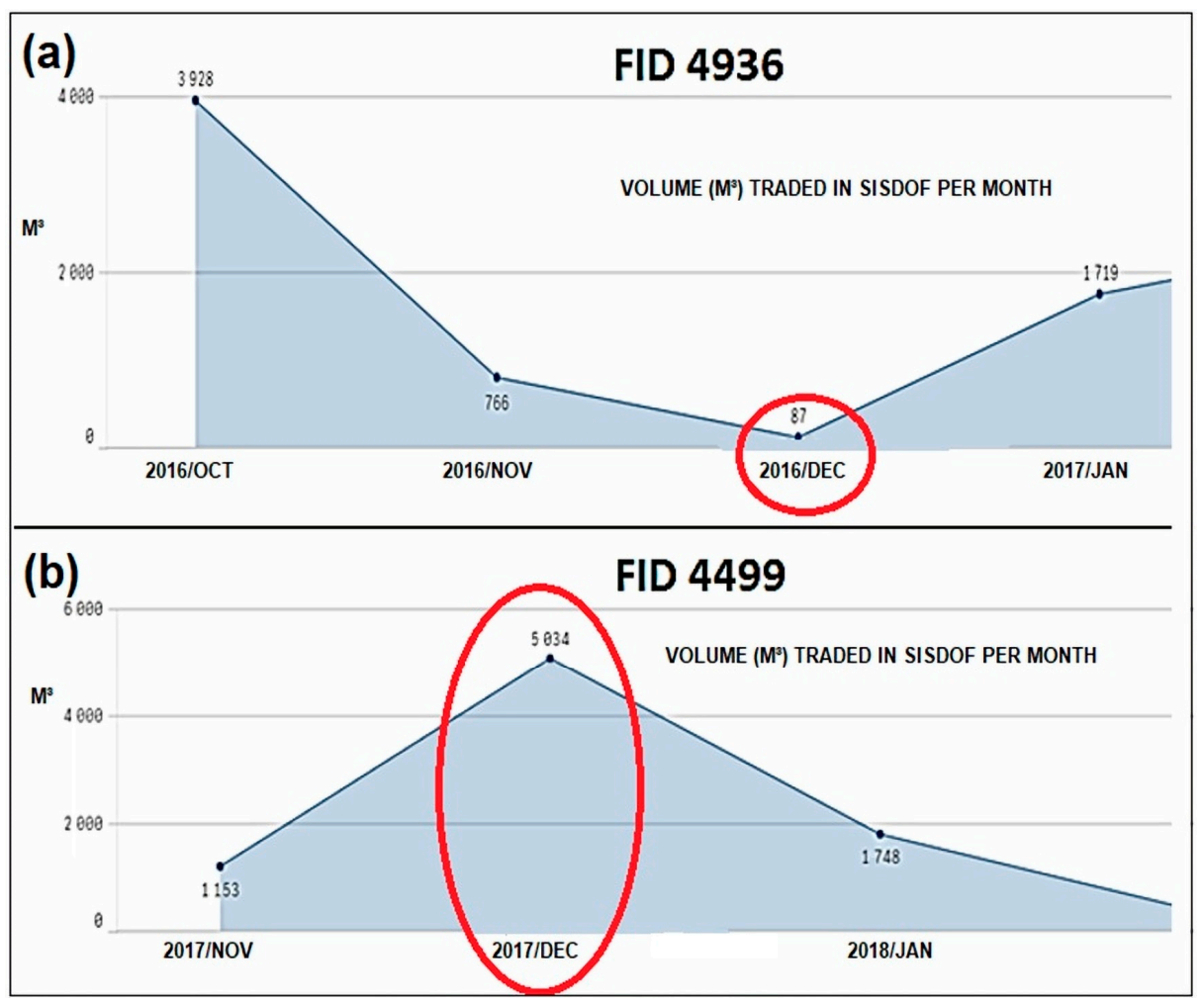

Figure 23. Monthly volume sold by FIDs 4999 (a) and 4936 (b). 
(iv) Criterion 2.4-Suspicious volume declared

STATE OF AMAZONAS: 3.6\%.

MSA: $3.2 \%$.

STANDARD PMFS: $8 \%$.

MSA 83 PMFS: 52\% of all areas had volumes of roundwood sold with no decimal places. The majority of PMFS had occurrence values below 10\%. However, FID 2568 had 51.3\% of their volumes traded for roundwood with no declared decimal place, out of $44,508.86 \mathrm{~m}^{3}$, traded between July and December 2013.

(v) Criterion 2.5-Identity of Internet Protocol (IP) numbers

STATE OF AMAZONAS: $54.5 \%$.

MSA: $50.7 \%$.

STANDARD PMFS: $26.1 \%$

MSA 83 PMFS: 81\% of all properties had transactions in SisDOF registered with the same IP number, both for the transaction of issuing and receiving the cargo.

(vi) Criterion 2.6-Price under $\mathrm{R} \$ 66.00$

STATE OF AMAZONAS: $26.3 \%$.

MSA: $28.2 \%$.

STANDARD PMFS: $0 \%$.

MSA 83 PMFS: 70\% of the areas recorded log sale prices under R $\$ 66.00$. FID 3662 had an average value for all species was around $\mathrm{R} \$ 30.00 / \mathrm{m}^{3}$, with even lower prices as demonstrated below (Figure 24).

\begin{tabular}{|c|c|c|c|c|}
\hline SCIENTIFIC NAME & VOLUME & $M^{3} / H A$ & TOTAL AMOUNT & $\mathrm{RS} / \mathrm{M}^{3}$ \\
\hline & 7798.41 & 19.28 & $R \$ 239,741.85$ & 30.74 \\
\hline EPERUA OLEIFERA & 1785.49 & 4.42 & $\mathrm{R} \$ 72,460.13$ & 40.58 \\
\hline DINIZIA EXCELSA & 1488.97 & 3.68 & $\mathrm{R} \$ 18,355.85$ & 12.33 \\
\hline ALLANTOMA LINEATA & 812.88 & 2.01 & $R \$ 32,203.89$ & 39.62 \\
\hline TABEBUIASERRATIFOLIA & 669.98 & 1.66 & $\bar{R} \$ 10,319.76$ & 15.40 \\
\hline DIPTERYXODORATA & 527.42 & 1.30 & $\mathrm{R} \$ 7157.74$ & 13.57 \\
\hline HYMENOLOBIUM HETEROCARPUM & 430.42 & 1.06 & $\mathrm{R} \$ 5075.40$ & 11.79 \\
\hline GOUPIA GLABRA & 347.52 & 0.86 & $\mathrm{R} \$ 4553.74$ & 13.10 \\
\hline MANILKARA HUBERI & 333.40 & 0.82 & $R \$ 4597.85$ & 13.79 \\
\hline CARYOCAR MICROCARPUM & 333.36 & 0.82 & $R \$ 25,076.09$ & 75.22 \\
\hline PELTOGYNE PANICULATA & 326.19 & 0.81 & $R \$ 25,272.66$ & 77.48 \\
\hline ERISMA UNCINATUM & 250.00 & 0.62 & $\mathrm{R} \$ 27,947.45$ & 111.79 \\
\hline
\end{tabular}

Figure 24. Main species sold by FID 3662 and its prices.

(vii) Criterion 2.7-Volume declared is incompatible with vehicle

STATE OF AMAZONAS: $1 \%$. 
MSA: $0.3 \%$

STANDARD PMFS: $0 \%$.

MSA 83 PMFS: $4 \%$ of the properties declared volumes in DOFs of their issuance incompatible with the type of road transport informed. Although FID 3645 had only $0.5 \%$ of incompatibility, this amount is equivalent to a volume of about $500 \mathrm{~m}^{3}$. In turn, FID 3087 presented $81.4 \%$ of incompatibility, which despite the small volume handled by the project, is equivalent to $300 \mathrm{~m}^{3}$.

(viii) Criterion 2.8-Transport distance greater than $200 \mathrm{~km}$

STATE OF AMAZONAS: $1.3 \%$.

MSA: $1.8 \%$.

STANDARD PMFS: $0 \%$.

MSA 83 PMFS: Three areas ( $4 \%$ of the sample) had logs sold to buyers located more than 200 $\mathrm{km}$ away (FIDs 1325, 2759 and 4034). FIDs 1325 and 2759 turn out to be suspicious, but they would require fieldwork and further analysis for an adequate conclusion. FID 4034 had a very peculiar behavior with $100 \%$ of the total volume of lumber sold (total of $5777.33 \mathrm{~m}^{3}$ of roundwood) transported to the same lumber, $340 \mathrm{~km}$ far in straight line. This very same PMFS presented no infrastructure compatible with forest management (item 1.2), what strongly reinforces the possibility of carrying out fraudulent transactions in the DOF for the legalization of products from other areas. This suspicion is strongly reinforced, once it was verified the existence of transactions at SisDOF whose time between the issuance of the DOF and the alleged receipt of the cargo by the recipient was less than $10 \mathrm{~min}$, for an estimated distance of $340 \mathrm{~km}$ in a straight line.

(ix) Criterion 2.9-Transport speed higher than $40 \mathrm{~km} / \mathrm{h}$

STATE OF AMAZONAS: $3.1 \%$.

MSA: $3 \%$.

STANDARD PMFS: $0 \%$.

MSA 83 PMFS: $70 \%$ of the PMFS had DOFs issued whose total transport time and distance, between the sender and the receiver, would have resulted in an average speed greater than $40 \mathrm{~km} / \mathrm{h}$. FID 4034, also mentioned in the criterion 2.8, presented transport duration times that would result in speeds above $1000 \mathrm{~km} / \mathrm{h}$ (Figure 25).

\begin{tabular}{|c|c|c|c|c|c|}
\hline $\begin{array}{l}\text { SPEED } \\
\text { (KM/H) }\end{array}$ & VOLUME & DISTANCE (KM) & $\begin{array}{l}\text { DURATION OF } \\
\text { TRANSPORT } \\
\text { (MINUTES) }\end{array}$ & DEPARTURE & ARRIVAL \\
\hline & $5.777,33$ & & & & \\
\hline $10,200.8$ & 51,37 & 348.8 & 2 & $18 / 81 / 201718: 27: 04$ & 18/81/2017 18:29:15 \\
\hline 4680.8 & 58.84 & 348.8 & 5 & 01/07/2016 09:41:39 & 01/87/201609:46:26 \\
\hline 2840.8 & 52.59 & 348.8 & 10 & 14/06/201617:26:39 & 14/96/201617:36:28 \\
\hline 2048.8 & 54.91 & 348.8 & 10 & 11/87/201615:15:44 & 11/87/2016 15:25:54 \\
\hline 1360.8 & 54.54 & 348.8 & 15 & $11 / 87 / 281614: 47: 32$ & $11 / 97 / 281615: 92: 30$ \\
\hline 1200.8 & 59.35 & 348.8 & 17] & 14/06/2016 17:19:26 & 14/06/2016 17:36:49 \\
\hline 927.3 & 27.98 & 348.8 & 22 & 13/81/2016 09:41:56 & 13/81/2016 19:84:14 \\
\hline
\end{tabular}

Figure 25. Transport speed (FID 4034). 
(x) Criterion 2.10-Fines for irregularities in the SisDOF STANDARD PMFS: No (2014-18).

MSA 83 PMFS: $6 \%$ of properties had records of administrative infractions (fines) due to the finding of irregularities in the SisDOF. This finding is quite relevant if we consider that a much higher percentage of the properties analyzed here presented strong indications of irregularities related to SisDOF.

(xi) Criterion 2.11-Fines for irregularities in the PMFS

STANDARD PMFS: No (2014-18).

MSA 83 PMFS: $7 \%$ of the properties had records of administrative infractions (fines) for irregularities in the execution of PMFS. The observation in the previous criterion (2.10) also applies here.

(xii) Criterion 2.12-Irregularities related to the forestry inventory

STANDARD PMFS: No. The forestry inventory (species and $\mathrm{m}^{3} / \mathrm{ha}$ ) resulted compatible with official data (RADAM Project). The volumetric data of all transactions contained in SisDOF as also individually for the 5 most exploited species resulted conforming to Benford's law, both for the total volume, as well as the volume per hectare. The sum of the "Diameter at Breast Height" (DBH) values of all the specimens of one of the annual production unit also proved to be conforming.

MSA 83 PMFS: $54 \%$ of the properties presented volumetric information incompatible with RADAM Project survey and/or not conforming with Benford's Law.

(xiii) Criterion 2.13-Total volume traded identical to the authorized volume

STANDARD PMFS: No

MSA 83 PMFS: 02 PMFS (2\% of the sample) had a total volume traded identical to the volume estimated in the forestry inventory (FIDs 4622 and 2087). Three other areas had a rate of utilization much higher than that usually found in these cases (which varied in the current sample between 75 and $90 \%$ ). FID 4769 had 98\%, while FID 4086 had $98.5 \%$ and FID $4343,96 \%$.

(xiv) Criterion 2.14-Fines for labor law violations

STANDARD PMFS: No. (2014-18).

MSA 83 PMFS: One property (FID 3364) presented labor irregularities, totaling 21 fines applied by the Labor Activity Inspection Body. The same property also had 78 administrative fines from IBAMA for various environmental offenses, between 1996 and 2017. The sum exceeds R $\$ 50$ million (approximately US\$12 million in 20 February 2020), what reinforces that disrespect to labor legislation go hand in hand with environmental offenses in the Brazilian Amazon.

(xv) Criterion 2.15-Exploitation intensity over $25 \mathrm{~m}^{3} /$ ha

STANDARD PMFS: No. The cutting intensity in the standard PMFS was $13.81 \mathrm{~m}^{3} / \mathrm{ha}$ (2014-18).

MSA 83 PMFS: $5 \%$ of the PMFS has a cutting intensity greater than $25 \mathrm{~m}^{3} / \mathrm{ha}$, with emphasis on FID 4769, whose exploitation intensity reached $33.41 \mathrm{~m}^{3} / \mathrm{ha}(2014-18)$.

The complete evaluation of each of the 83 PMFS would require further analysis by obtaining complete documentation and conducting on-site inspections, in order to confirm the irregularities and estimate the extension of the environmental damage. However, the results obtained provided an overview of the multiple possibilities and the importance of GEOINT for the assessment of PMFS.

Table 3 shows the frequency and percentage of PMFS that presented each of the irregularities or signs of fraud evaluated, according to the criteria previously described in Table 2. 
Table 3. Frequency (f) and percentage (\%) of irregularities/signs of fraud.

\begin{tabular}{llc}
\hline 1.Criteria For Spatial Data & $\mathbf{f}$ & $\%$ \\
\hline 1.1 Total or partial overlap of PMFS area with protected areas & 8 & $10 \%$ \\
1.2 Lack of infrastructure compatible with PMFS (courtyard and roads) & 20 & $24 \%$ \\
1.3 Clear cut inside PMFS or Areas of Permanent Preservation (APP) & 36 & $43 \%$ \\
1.4 Forestry activities in the area prior to licensing & 16 & $19 \%$ \\
1.5 Further forest exploitation after the last DOF issuing & 4 & $5 \%$ \\
1.6 Exploitation held outside the polygon boundaries & 42 & $51 \%$ \\
1.7 Exploitation in area previous embargoed by IBAMA & 0 & $0 \%$ \\
\hline 2.Criteria For Non-Spatial Data & $\mathbf{f}$ & $\%$ \\
\hline 2.1 Product received after valid dates & 14 & $17 \%$ \\
2.2 DOF Canceled & 17 & $20 \%$ \\
2.3 DOF issued during rainy season & 20 & $24 \%$ \\
2.4 Suspicious volume declared & 43 & $52 \%$ \\
2.5 Identity of IP numbers & 67 & $81 \%$ \\
2.6 Price under R $\$ 66.00$ & 58 & $70 \%$ \\
2.7 Volume declared is incompatible with vehicle & 3 & $4 \%$ \\
2.8 Distance greater than $200 \mathrm{~km}$ & 3 & $4 \%$ \\
2.9 Transport speed higher than $40 \mathrm{~km} /$ hour & 58 & $70 \%$ \\
2.10 Fines for irregularities in the SisDOF & 5 & $6 \%$ \\
2.11 Fines for irregularities in the PMFS & 6 & $7 \%$ \\
2.12 Irregularities related to the forestry inventory & 45 & $54 \%$ \\
2.13 Total volume traded identical to the authorized volume & 2 & $2 \%$ \\
2.14 Fines for labor law violations & 1 & $1 \%$ \\
2.15 Exploitation intensity over $25 \mathrm{~m}^{3} /$ ha & 4 & $5 \%$ \\
\hline
\end{tabular}

Individual data and results for each of the 83 PMFS as images, maps, and graphs are available in the Supplementary Materials.

\section{Discussion}

The analysis of images and other spatial data allowed us to evaluate the current situation of forestry exploitation carried out in the 83 PMFS submitted to examination, identifying, among other points: (i) possible overlap with protected areas; (ii) where and when forest exploitation took place; (iii) what type and intensity of this exploitation (clear cut, selective cutting, opening of roads, yards etc.); (iv) its dimensions; and (v) the regularity of exploitation in relation to the authorized polygon and the areas of permanent preservation (APP).

In its turn, the analysis of non-spatial data (documents and databases obtained from public agencies) allowed for a better understanding of the entire context in which the obtained geographic information is inserted, notably: (i) if the referred exploitation took place in an authorized area and, if so, if it was carried out in accordance with the respective authorization, its conditions and limits; (ii) if the transport and sale of these forest products followed the respective legal procedure (there are no inconsistencies or evidence of fraud), with the wood being effectively delivered to the informed recipient; and (iii) or, if on the other hand such data, when analyzed together with the spatial information, point to the existence of evidence of fraud in the forest inventories (overestimation of volumes of higher value commercial species) as well as the existence of a transaction commercial and/or transport simulated in the respective systems, just to legalize forest products illegally extracted from other areas. Table 4 shows the frequency ranking by the criteria previously described in Table 2 . 
Table 4. Frequency ranking by criteria.

\begin{tabular}{|c|c|c|c|}
\hline Ranking & Criteria & f & $\%$ \\
\hline 1 st & 2.5 Identity of IP numbers & 67 & $81 \%$ \\
\hline \multirow{2}{*}{ 2nd } & 2.6 Price under $\mathrm{R} \$ 66.00$ & 58 & $70 \%$ \\
\hline & 2.9 Transport speed higher than $40 \mathrm{~km} /$ hour & 58 & $70 \%$ \\
\hline 4 th & 2.12 Irregularities related to the forestry inventory & 45 & $54 \%$ \\
\hline 5 th & 2.4 Suspicious volume declared & 43 & $52 \%$ \\
\hline 6th & 1.6 Exploitation held outside the polygon boundaries & 42 & $51 \%$ \\
\hline 7 th & 1.3 Clear cut inside PMFS or Areas of Permanent Preservation (APP) & 36 & $43 \%$ \\
\hline \multirow{2}{*}{ 8th } & 1.2 Lack of infrastructure compatible with PMFS (courtyard and roads) & 20 & $24 \%$ \\
\hline & 2.3 DOF issued during rainy season & 20 & $24 \%$ \\
\hline 10th & 2.2 DOF Canceled & 17 & $20 \%$ \\
\hline 11th & 1.4 Forestry activities in the area prior to licensing & 16 & $19 \%$ \\
\hline 12th & 2.1 Product received after valid dates & 14 & $17 \%$ \\
\hline 13th & 1.1 Total or partial overlap of PMFS area with protected areas & 8 & $10 \%$ \\
\hline 14th & 2.11 Fines for irregularities in the PMFS & 6 & $7 \%$ \\
\hline 15 th & 2.10 Fines for irregularities in the SisDOF & 5 & $6 \%$ \\
\hline \multirow{2}{*}{ 16th } & 1.5 Further forest exploitation after the last DOF issuing & 4 & $5 \%$ \\
\hline & 2.15 Exploitation intensity over $25 \mathrm{~m}^{3} / \mathrm{ha}$ & 4 & $5 \%$ \\
\hline \multirow{2}{*}{ 18th } & 2.7 Volume declared is incompatible with vehicle & 3 & $4 \%$ \\
\hline & 2.8 Distance greater than $200 \mathrm{~km}$ & 3 & $4 \%$ \\
\hline 20th & 2.13 Total volume traded identical to the authorized volume & 2 & $2 \%$ \\
\hline $21 \mathrm{st}$ & 2.14 Fines for labor law violations & 1 & $1 \%$ \\
\hline 22nd & 1.7 Exploitation in area previous embargoed by IBAMA & 0 & $0 \%$ \\
\hline
\end{tabular}

With regard to the assessment of possible fraud in forest inventories, it should be noted that during the analysis work, it was possible to demonstrate that the volumetric data contained in the forest inventories (and, therefore the volume data of wood marketed through SisDOF) were expected to conform to the mathematical model known as Benford's law [51], which has long been used to detect economic and financial fraud.

The analysis, carried out using data from official forest inventories across the Southern Mesoregion of Amazonas, showed that this model can be applied to the following volumetric datasets: (i) total volume (by species or per hectare); (ii) number of specimens (total per species or per hectare); and (iii) sum of the diameter at breast height (DBH) values of all specimens, by species.

It was also found that the volumetric data traded in the State of Amazonas of Tabebuia serratifolia (ipê), a species that is known to have been fraudulently overestimated in forest inventories due to its high commercial value [12], were not in conformity with Benford's law. This observation reinforces the importance of the methodology used in this investigation and opens up a new range of possibilities for the realization of truly sustainable management in the Brazilian Amazon.

Nonetheless, we are aware that the analyses and results herein obtained have limitations, especially those related to the low spatial resolution of the satellite images used and the frequent presence of clouds in the region. Such limitations, however, refer exclusively to the option of using images available to the general public and not to specific limitations of the GEOINT methodology employed, which can be easily overcome with the acquisition of images with higher spatial resolution and those produced by radars. 


\section{Conclusions}

Combined analysis of spatial and non-spatial data allowed for a better understanding of the context of each PMFS, especially as evidence of simulated transactions to legalize forest products extracted illegally from other areas. Low/medium resolution imagery can be used to identify selective logging infrastructure (access road and storage yards). Collateral material has paramount importance in understanding the imagery and geospatial information context as well as in reaching robust conclusions about the legality of forestry activities in a specific area. Business intelligence tools are valuable for analyzing and processing a large amount of collateral material, allowing for the results to be produced faster, as they discover hidden patterns in data. Benford's law is valuable for evaluating forestry inventory data and is useful for detecting possible fraud.

Supplementary Materials: The following supplementary materials are available online at http://www.mdpi. com/2220-9964/9/6/398/s1, Forty-one summary sheets, in Portuguese language, with the following structure: (i) identification of evaluated PMFS (by its FID); (ii) checklist containing the 22 criteria evaluated and notes/observations; and (iii) main images and graphics produced during the analyses. One electronic control spreadsheet containing: (i) identification of each of the PMFS evaluated by its summary sheet number and FID; (ii) results in Boolean format for each one of the 22 criteria evaluated; (iii) summary of the total amount of irregularities or indications of fraud detected, divided into four categories (irregularities in the execution of the PMFS; indications of fraud in the SisDOF; indications of fraud in the forest inventory; and; irregularities related to labor regulations).

Author Contributions: Conceptualization and methodology, Franco Perazzoni, Paula Bacelar-Nicolau, and Marco Painho; Supervision, Paula Bacelar-Nicolau and Marco Painho; Validation, Franco Perazzoni, Paula Bacelar-Nicolau, and Marco Painho; Investigation, Franco Perazzoni, Paula Bacelar-Nicolau, and Marco Painho; Writing-Review \& Editing, Franco Perazzoni, Paula Bacelar-Nicolau, and Marco Painho. All authors have read and agreed to the published version of the manuscript.

Funding: This research received no external funding.

Acknowledgments: The authors would like to acknowledge the Division of Crimes against the Environment of Brazilian Federal Police (DMAPH/PF) as well as the Management and Operational Center for the Amazon Protection System (CENSIPAM) and Mil Madeiras Ltd.a., for providing the spatial and non-spatial data.

Conflicts of Interest: The authors declare no conflict of interest.

\section{References}

1. Instituto Nacional de Pesquisas Espaciais (INPE). Divisão de Geração de Imagens. Available online: http://www.dgi.inpe.br (accessed on 20 January 2020).

2. Instituto do Homem e Meio Ambiente da Amazônia. Mercado e Preços da Madeira Amazônica; Imazon: Belém, Brazil, 2010.

3. Pontes, R.V.; Noronha, M.C.; Pontes, K.R. Desflorestamento no sul do Amazonas: Embate entre o desenvolvimento econômico e a conservação ambiental. Am. Res. Thoughts 2015, 1, 1551-1570.

4. Código Florestal Brasileiro. Lei Federal No. 12.651/2012. Available online: http://www.planalto.gov.br/ccivil_ 03/_ato2011-2014/2012/lei/112651.htm (accessed on 12 December 2019).

5. Trennepohl, C.; Trennepohl, T. Licenciamento Ambiental, 7th ed.; Revista dos Tribunais: São Paulo, Brazil, 2018.

6. Perazzoni, F. Criminalidade Ambiental Organizada: O Desmate Ilegal em Mato Grosso; Fórum Nacional de Segurança Pública: São Paulo, Brazil, 2009.

7. Perazzoni, F. Amazonia, Organized Crime and Illegal Deforestation: Best Practices for the Protection of the Brazilian Amazon. In The 21st Century Fight for the Amazon: Environmental Enforcement in the World's Biggest Rainforest; Ungar, M., Ed.; Palgrave Macmillan: New York, NY, USA, 2018; pp. 21-56.

8. Instituto Brasileiro do Meio Ambiente e Recursos Naturais Renováveis. IBAMA. Documento de Origem Florestal (DOF); Ministério do Meio Ambiente: Brasília, Brazil. Available online: https://www.ibama.gov.br/ flora-e-madeira/dof/o-que-e-dof (accessed on 20 January 2020).

9. Perazzoni, F. Curso de Combate a Crimes Contra a Flora. Divisão de Repressão aos Crimes Ambientais e Contra o Patrimônio Histórico, Polícia Federal; Academia Nacional de Polícia: Brasília, Brazil, 2012.

10. Perazzoni, F. Geointeligência no Combate ao Desmatamento ilegal na Amazônia: Polícia Federal e Sistemas de Informação Geográfica; Nuria Fabris: Porto Alegre, Brazil, 2014. 
11. Arruda, R.M. Crime Contra a Flora: Quando a Ofensa Evolui, a Investigação Também Precisa Evoluir. Monograph; Post-graduate Program in Criminal Investigation, Escola Superior de Polícia, Ministério da Justiça: Brasília, Brazil, 2014.

12. Brancalion, P.H.; Almeida, D.R.; Vidal, E.; Molin, P.G.; Sontag, V.E.; Souza, S.E.; Schulze, M.D. Fake legal logging in the Brazilian Amazon. Sci. Adv. 2018, 4. [CrossRef] [PubMed]

13. Greenpeace. Imaginary Trees, Real Destruction. How Licensing Fraud and Illegal Logging of Ipe Trees Are Causing Irreversible Damage to the Amazon Rainforest. 2018. Available online: https://www.greenpeace.org. br/hubfs/Greenpeace_Report_Imaginary_Trees_Real_Destruction_March_2018.pdf (accessed on 20 January 2020).

14. Dittmar, H.; Perazzoni, F. Desmatamento Ilegal na mira da Polícia Federal. Perícia Federal 2011, 28, 19-22.

15. Stone, T.; Lefebvre, P. Using multi-temporal satellite data to evaluate selective logging in Para, Brazil. Int. J. Remote Sens. 1998, 19, 2517-2526. [CrossRef]

16. National Geospatial-Intelligence Agency (NGA). National System for Geospatial Intelligence (GEOINT) Basic Doctrine; National Geospatial-Intelligence Agency: Springfield, MA, USA, 2006. Available online: http: //www.fas.org/irp/agency/nga/doctrine.pdf (accessed on 20 January 2020).

17. Conselho Estadual de Meio Ambiente do Estado do Amazonas (CEMAN). Resoluçãro N. 30 de 31 de Outubro de. 2018. Available online: http://meioambiente.am.gov.br/wp-content/uploads/2018/02/30.RESOLUÇÃO-Nº-30-PMFS.pdf (accessed on 12 December 2019).

18. Souza, C., Jr.; Barreto, P. An alternative approach for detecting and monitoring selective logged forests in the Amazon. Int. J. Remote Sens. 2000, 21, 173-179. [CrossRef]

19. Asner, G.; Keller, M.; Pereira, R.; Zweede, J. Remote Sensing of selective logging in Amazonia Assessing limitations based on detailed Field observations, Landsat ETM+, and textural analysis. Remote Sens. Environ. 2002, 80, 483-496. [CrossRef]

20. Asner, G.; Knapp, D.; Broadbent, E.; Oliveira, P.; Keller, M.; Silva, N. Selective logging in the Brazilian Amazon. Science 2005, 310, 480-482. [CrossRef] [PubMed]

21. Graça, P.A.; Santos, J.R.; Soares, J.V. Desenvolvimento metodológico para detecção e mapeamento de áreas florestais sob exploração madeireira: Estudo de caso, região norte do Mato Grosso. In Proceedings of the Anais XII Simpósio Brasileiro de Sensoriamento Remoto INPE, Goiânia, Brazil, 16-21 April 2005; pp. 1555-1562.

22. Monteiro, A.; Souza, C., Jr. Imagens de Satélite Para Avaliar Planos de Manejo Florestal; Imazon: Belém, Brazil, 2006.

23. Monteiro, A.; Souza, C., Jr. Fotografias hemisféricas para validar o monitoramento da qualidade do manejo florestal na Amazônia Legal. In Proceedings of the Anais XVI Simpósio Brasileiro de Sensoriamento Remoto, INPE, Natal, Brazil, 25-30 April 2009; pp. 6013-6020.

24. Cardoso, G.F.; Costa, J.A.; Viana, J.S.; Tancredo, N.S. Uso de Imagens NDFI para Identificar Áreas de Exploração Irregular de Madeira em Ações de Fiscalização. In Proceedings of the Anais do XV Simpósio Brasileiro de Sensoriamento Remoto, INPE, Curitiba, Brazil, 30 April-04 May 2011; pp. 2856-2862.

25. Dittmar, H. Aplicação do Índice de Vegetação por Diferença Normalizada (NDVI) em estudos de caracterização da vegetação. Perícia Fed. 2013, 31, 41-46.

26. Pinage, E.R.; Matricardi, E.T. Detecção da Infraestrutura para Exploração Florestal em Rondônia Utilizando Dados de Sensoriamento Remoto. Floresta E Ambiente 2015, 22, 377-390. [CrossRef]

27. Pantoja, N.V.; Higuchi, N.; d' Oliveira, M.N. Detecção da exploração madeireira a partir de imagens Landsat e dados LiDAR no Sudoeste da Amazônia. In Proceedings of the XVIII Simpósio Brasileiro de Sensoriamento Remoto, Santos, Brazil, 28-31 May 2017.

28. Associação de Polícias das Américas. Geonteligência no combate ao crime ambiental: O projeto GAGeo da Polícia Federal do Brasil. In Buenas Práticas; AMERIPOL: Bogotá, Colombia, 2015.

29. Pereira, B.M. Uso de Geointeligência como ferramenta de investigação, pela Polícia Federal, nos crimes de desmatamento. Rev. Bras. De Ciências Polic. 2017, 8, 63-97. [CrossRef]

30. United States Geological Survey (USGS). Earth Explorer. Available online: https://earthexplorer.usgs.gov/ (accessed on 20 January 2019).

31. Instituto de Proteção Ambiental do Amazonas (IPAAM). Geodatabase of polygons of Sustainable Forestry Management Plannings (PMFS) in the State of Amazonas; IPAAM: Manaus, Brazil, 2017.

32. Fundação Nacional do Índio (FUNAI). Shapefile of Brazilian Indigenous Lands; Ministério da Justiça: Brasília, Brazil. Available online: http://www.funai.gov.br/index.php/shape (accessed on 12 February 2019). 
33. Instituto Chico Mendes de Biodiversidade (ICMBIO). Shapefile of Brazilian Conservation Units; Ministério do Meio Ambiente: Brasília, Brazil. Available online: http://www.icmbio.gov.br/portal/images/stories/servicos/ geoprocessamento/DCOL/dados_vetoriais/UC_fed_julho_2019.zip (accessed on 12 February 2019).

34. Instituto Brasileiro de Geografia e Estatística (IBGE). Geociências. Available online: https://www.ibge.gov.br/ geociencias/downloads-geociencias.html (accessed on 12 February 2019).

35. Instituto Nacional de Colonização e Reforma Agrária (INCRA). Acervo Fundiário. Shapefile of Areas Destinated To Land Reform. Available online: http://acervofundiario.incra.gov.br/acervo/acv.php (accessed on 11 January 2019).

36. Instituto Brasileiro do Meio Ambiente e dos Recursos Naturais Renováveis (IBAMA). Inspection Reports on Forestry Management Areas. Jan/01/2014 to Aug/21/2018; Ministério do Meio Ambiente: Brasília, Brazil, 2018.

37. Polícia Federal do Brasil. Forensic Reports on Forestry Management Areas. Jan/200 to Aug/2017; Ministério da Justiça: Brasília, Brazil, 2012.

38. Instituto Brasileiro de Geografia e Estatística (IBGE). Banco de Informações Ambientais. Projeto RADAM Brasil. Available online: Ftp://geoftp.ibge.gov.br/informacoes_ambientais/vegetacao/vetores/escala_1000_ mil_radambrasil/ (accessed on 12 February 2020).

39. Instituto Brasileiro do Meio Ambiente e Recursos Naturais Renováveis (IBAMA). Embargo and Administrative Fines Data. Jan/1996 to Dec/2017; Ministério do Meio Ambiente: Brasília, Brazil, 2018. Available online: https: //servicos.ibama.gov.br/ctf/publico/areasembargadas/ConsultaPublicaAreasEmbargadas.php (accessed on 12 December 2019).

40. Secretaria de Trabalho (STME). Administrative Fines Data; Ministério da Economia: Brasília, Brazil, 2019. Available online: http://cdcit.mte.gov.br/inter/cdcit/emitir.seam (accessed on 12 December 2019).

41. Instituto Brasileiro do Meio Ambiente e Recursos Naturais Renováveis (IBAMA). Vehicles Authorized to Transport Forest Products in the Amazon and Their Carrying Volume Capacity; Ministério do Meio Ambiente: Brasília, Brasil, 2019.

42. Instituto Brasileiro do Meio Ambiente e dos Recursos Naturais Renováveis (IBAMA). Sistema de Controle do Documento de Origem Florestal (SisDOF). Trade data on SisDOF for the State of Amazonas. Jan/01/2014 to Aug/21/2018; Ministério do Meio Ambiente: Brasília, Brazil, 2018.

43. Kahaner, L. Competitive Intelligence: How to Gather, Analyze and Use Information to Move Your Business to the Top; Touchstone: New York, NY, USA, 1997.

44. Meillón, S. Geospatial Intelligence and Geospatial Information Systems; NPS-Naval Postgraduation School: Monterey, CA, USA, 2008.

45. Forest Stewardship Council. FSC. Available online: http://www.fsc.org (accessed on 20 January 2019).

46. Mil Madeiras Ltd. Projeto do Plano de Manejo da Mil Madeiras; Mil Madeiras: Itacoatiara, Brazil, 2018.

47. Clay, J.W.; Amaral, P. Madeira tropical sustentável de florestas naturais: O caso da Precious Woods. In Esverdeando a Amazônia; IIEB: São Paulo, Brazil, 2002; pp. 163-191.

48. Franca, R.R.; Mendonça, F.A. A Pluviosidade na Amazônia Meridional: Variabilidade e Teleconexões Extra-Regionais. Confins, 29. 2016. Available online: http://journals.openedition.org/confins/11580 (accessed on 20 January 2019). [CrossRef]

49. Fidelis, L.R.; Dittmar, H. Forensic Report \# 120/2016-SR/PF/MA. Brazilian Federal Police; Setor Técnico Científico da Polícia Federal: São Luís, Brazil, 2016.

50. Silva, Z.A. Raio Econômico como um Indicativo para a Definição de Concessões Florestais: Um Estudo de Caso no Estado do Acre; II Prêmio Serviço Florestal Brasileiro em Estudos de Economia e Mercado Florestal: Brasília, Brazil, 2015.

51. Benford, F. The law of anomalous numbers. Proc. Am. Philos. Soc. 1938, 78, 551-572.

52. Carnegie Institution for Science. CLASlite Software. 2013. Available online: http://claslite.carnegiescience. edu/en/about/software.html (accessed on 2 September 2019).

53. Asner, G.P. Biophysical and biochemical sources of variability in canopy reflectance. Remote Sens. Environ. 1998, 64, 234-253. [CrossRef]

54. Rouse, J.W.; Haas, R.H.; Schell, J.A.; Deering, D.W. Monitoring vegetation systems in the Great Plains with ERTS. In Proceedings of the Third ERTS Symposium, SP351 Goddard Space Flight Center, Washington, DC, USA, 10-14 December 1973; pp. 309-317.

55. Shimabukuro, Y.E. Shade Images Derived from Linear Mixing Models of Multispectral Measurements of Forested Areas. Ph.D. Thesis, Colorado State University, Fort Collins, CO, USA, 1987. 
56. Miller, S.J. Excel Program to test for Benfordness. 2015. Available online: https://web.williams.edu/ Mathematics/sjmiller/public_html/benford/chapter01/MillerNigrini_ExcelBenfordTester_Ver401.xlsx (accessed on 20 February 2020).

57. Hales, D.N.; Sridharan, V.; Radhakrishnan, A.; Chakravorty, S.S.; Siha, S.M. Testing the accuracy of employee-reported data: An inexpensive alternative approach to traditional methods. Eur. J. Oper. Res. 2008, 189, 583-589. [CrossRef]

58. Nigrini, M. A taxpayer compliance application of Benford's law. J. Am. Tax. Assoc. 1996, 1, 72-91.

59. Amaral, F. Introdução à Ciência de Dados: Mineração de dados e Big Data; Alta Books: Rio de Janeiro, Brazil, 2016.

60. Newcomb, S. Note on the Frequency of Use of the Different Digits in Natural Numbers. Am. J. Math. 1881, 4, 39-40. Available online: http://www.uvm.edu/pdodds/files/papers/others/1881/newcomb1881a.pdf (accessed on 4 February 2020). [CrossRef]

C 2020 by the authors. Licensee MDPI, Basel, Switzerland. This article is an open access article distributed under the terms and conditions of the Creative Commons Attribution (CC BY) license (http://creativecommons.org/licenses/by/4.0/). 